\title{
DEMAND FOR THE TRUTH IN PRINCIPAL-AGENT RELATIONSHIPS
}

\author{
Joshua Ronen*
}

Varda (Lewinstein) Yaari**

July 2006

* Department of Accounting, Taxation, and Business Law, Stern School of Business, New York University, 310 Tisch Hall, NYC 10012-1118, jronen@ stern.nyu.edu.

** Department of Business Administration, School of Management, Ben-Gurion University, Beer-Sheva, Israel 84105, alexgum21@ hotmail.com

Acknowledgements: We are grateful to the participants in the First World Congress of the Game Theory Society, Bilbao, Spain, July 2000, where we first presented our project, Renegotiation-Proof PrincipalAgent Contracts with Unobservable Outcome; to the participants in the conference on New Directions in Management Accounting in Brussels, Belgium, December 2000; to the participants in the AAA meeting in Atlanta, 2001, and, in particular, to our discussant, Pierre Jinghong Liang; to the participants in the European Accounting Associating Meeting, Copenhagen, Denmark, April 2002; and to the participants in the Accounting and the Economics conference in Madrid, Spain, May 2002, and, in particular, to our discussant, D. Pfaff. We have benefited from the comments of seminar participants at Tel-Aviv University, Ben-Gurion University of the Negev, and the University of Maryland. The second author acknowledges the hospitability of Baruch College, with warm thanks to Masako Darrough and Aloke Ghosh. While we have benefited from valuable discussions with Joe Kerstein, Arieh Gavious, Avi Vohl, Ramy Elitzur, Hila Yaari, and Bharat Sarath, the responsibility for any remaining mistakes is solely ours. We are especially indebted to our editor, Jerry Feltham, for numerous suggestions that have improved the paper in content and form. 


\title{
DEMAND FOR THE TRUTH IN PRINCIPAL-AGENT RELATIONSHIPS
}

\begin{abstract}
Consider the following puzzle: If earnings management is harmful to shareholders, why don't they design contracts that induce managers to reveal the truth? To answer this question, we model the shareholders-manager relationship as a principal-agent game in which the agent (the manager) alone observes the economic outcome. We show that the limited liability of the agent, defined as the agent's feasible minimum payment, might explain the demand for earnings management by the principal. Specifically, when the limited-liability level is high (low), a contract that induces earnings management may be less (more) costly than a truthrevealing contract. This finding offers a new explanation of the demand for earnings management.
\end{abstract}

Key words: Limited liability, Principal-agent contract, Report management, Revelation Principle. 
The recent events that shook the credibility of financial accounting reports raise a question regarding the participation of shareholders in the earnings management process. In particular, since shareholders and managers act as principal and agent, why don't the former design a truth-inducing contract if earnings management is so harmful, especially since a truth-inducing contract is likely to be less costly than non-truth-inducing contracts (see, e.g., Lambert, 2001)?

Previous studies have offered one of two explanations: either eliciting the truth is not feasible (see Arya, Glover, and Sunder, 2002), or the truth is costly to the principal for external reasons beyond the principal-agent relationship per se (see Ronen and Yaari, 2002). ${ }^{12}$,

In this study, we provide yet another explanation that focuses on the limited-liability (LL) of the agent, LL, which places a lower bound on the compensation that can be paid to the agent. We study a one-shot principal-agent game in which the agent alone observes the outcome. We study two contracts: A report-management inducing contract (RMC) and a truth-inducing contract (TIC). In the RMC regime, the agent (management) reports the outcome to the auditor and the auditor in return reports an audited outcome to the principal (investors). The auditor does not tell the principal whether his reported outcome is the same as what the agent reported to him. The report to the principal depends on the degree of reporting flexibility that determines the maximum bias in the report, and the probability that the imperfect audit detects the truth. In the TIC regime, the agent privately reports the

\footnotetext{
${ }^{1}$ Arya, Glover, and Sunder (2002) and Ronen and Yaari (2002) present circumstances in which no truthinducing contract can achieve a superior payoff. The former study is a review of analytical research that establishes the value of earnings management in principal-agent contracts when the Revelation Principle does not hold. The latter focuses on the Revelation Principle's confidentiality requirement: the agent is supposed to communicate the truth to the principal confidentially, since, if it is aware of such communication, a third outside party can induce public disclosures that are undesirable to the principal.

${ }^{2}$ For example, a company many not wish to reveal adverse information that could cause a drop in its shares' price below a threshold level, which in turn could trigger harmful consequences due to contractual provisions with creditors.
} 
outcome to the auditor and the principal; the two reported outcomes can differ and neither the auditor nor the principal knows what was reported to the other. The contractible information consists of the auditor's report and the agent's report to the principal. The principal can compare the two reported outcomes and then penalize the agent if the audited report differs from the agent's private report to the principal.

In the first part of the paper, we characterize the shape of the LL contracts. We find that although LL introduces flat regions into both contracts, LL affects the RMC and TIC contracts differently. Consider first the RMC. We show that under plausible conditions on technology and the degree of reporting flexibility, RMC is a strictly increasing function of reported outcome. Introducing LL forces payments for low reported outcomes to be set at the newly introduced LL level, even when such payments would have been lower in the absence of limited liability. Hence, an RMC is a piece-wise contract with a single flat step (the lowest, leftmost region), but a smooth upward rising schedule thereafter (see Figure 2). Increasing the LL level would increase the width of the flat step. However, the flat step cannot include the highest reported outcome: if it did, the contract would consist of a flat wage for all reported outcomes, thus providing no incentives to exert effort.

In a TIC, the risk-averse agent reports the truth because the truth earns him the certainty equivalent of a lottery between a payment upon a successful overstatement (reporting a "target report" that earns him more than the truth does) and a penalty upon unsuccessful misrepresentation; the penalty cannot fall below the LL level. LL creates a step in the compensation schedule when (i) the reporting flexibility allows for different outcomes to share the same "target report" payment, and (ii) LL constrains the principal to design the 
same penalty for different reported outcomes. Consequently, a TIC is a non-decreasing function with a few steps. ${ }^{3}$

Our major insight is that if LL is sufficiently high, the principal may prefer report management. This happens when RMC is less costly than TIC. With high LL level, whether a TIC is more costly than RMC depends on the degree of reporting flexibility, and the agent's level of risk aversion. Flexibility impacts the riskiness of the RMC, because it determines the range of realized outcomes for which the agent faces a lottery between the LL level and the maximum payment. As flexibility increases, this range increases as well (see Figure 4). This higher riskiness, in turn, induces the agent more effectively to exert effort, thus allowing the principal to decrease the maximum payment. ${ }^{4}$

Consider now the TIC when the LL level is high. As the analysis shows, truth elicitation requires that each payment equals the certainty equivalent of a lottery between the LL level and highest payment in the off-equilibrium event of the maximum misrepresentation allowed under the given reporting flexibility. Such certainty equivalent always exceeds the LL level, reserving the latter as payment for the off-equilibrium event that a misrepresentation is detected. Over the range of reported outcomes for which the agent faces a lottery in a RMC, the comparison between the expected value of such a lottery and the corresponding certainty equivalent payments in TIC depends on the degree to which the maximum payment in TIC exceeds the maximum payment in RMC, as well as on the agent's degree of risk-aversion.

\footnotetext{
${ }^{3}$ To illustrate, consider a 7-outcome example, in which the lowest outcome is Outcome 1 and the highest outcome is Outcome 7. Suppose the reporting flexibility allows reporting at most three higher outcomes with some chance of the misrepresentation not being detected by the auditor. That is, if Outcome 1 is realized, reporting Outcomes 2, 3, or 4 is feasible; if Outcome 2 is realized, reporting 3, 4, or 5, is feasible and so on. Suppose that the agent has incentives to report the highest report that might escape detection. Outcome 7 then is the "target report" of Outcomes 4, 5, and 6. Clearly, since Outcomes 4, 5 and 6 share the same gamble between truth-telling and misrepresentation, the payment that induces a truthful report of any of them induces truthful reports of the remaining two. This creates a "step" in the compensation schedule for Outcomes 4-6. Since Outcomes 4-6 are "target reports" for Outcomes 1-3, a similar argument establishes that the contract has three steps: $1-3,4-6$, and 7.

${ }^{4}$ With low flexibility, the maximum payment must be higher to induce the desired level of effort since the risk otherwise imposed on the agent would be too low.
} 
There exist configurations wherein a lower maximum payment in RMC caused by high degree of flexibility (see above discussion), a high level of LL, and low risk-aversion of the agent cause the RMC to be less costly than TIC (see Figure 6).

Our study contributes to the earnings management literature that focuses on internal demand for earnings management, which stems from the principal-agent relationship between shareholders and the manager (e.g., Dye [1988], Evans and Sridhar [1996], Demski, Frimor, and Sappington [2004], Gao [2006], and Ronen, Tzur, and Yaari [2006]). Both first studies assume that the principal is unable to elicit the truth: his only alternative to basing the contract on the managed report is to offer the agent a flat wage. Because a flat wage creates disincentives to exert effort, a report-management equilibrium is "the lesser of two evils." Dye, for example, notes: "[A] necessary condition for the existence of an internal demand for management is that some dimension of management's private information cannot be costlessly communicated" (p.200). He also observes that truth-telling is prohibitively costly (Proposition 1). We, however, allow for the possibility of designing a TIC and are concerned with the conditions that make such a contract more costly than an RMC: high LL, high accounting flexibility, and low agent's risk aversion.

In the last three studies, earnings management prevention is costly because it diverts effort of either the agent (Demski, Frimor, and Sappington [2004]) or the board of directors (Gao[2006]) away from productive activity. In the Ronen, Tzur, and Yaari study, prevention is costly because the board wishes to avoid conflict with management; Furthermore the informed board benefits from earnings management by making insider trading gains. In the present study, the only cost giving rise to earnings management is generated by the agent 's LL. If the LL level is low, the principal demands the truth.

Our results also contribute to the research on LL principal-agent contracts. In the accounting literature, Kwon, Newman, and Suh (2001) establish the value of conservatism as 
a mechanism that compensates for the principal's inability to design low-outcome payments that are lower than the agent's LL level. To the best of our knowledge, our paper is the first study to analyze how LL may affect the demand for earnings-management.

The seminal paper of Sappington (1983) opened the field of research on contract design for a risk-neutral agent with limited liability, followed by Demski, Sappington, and Spiller (1988); Innes (1990); Park (1995); Kim (1997); Basu, Bell, and Bose (2000); Demougin and Fluet (1998, 2001); Laux (2001); Matthews (2001), and others. As Harris and Raviv (1979) have shown, when a principal contracts with a risk-neutral agent with unlimited wealth, a firstbest contract is feasible by selling the enterprise to the agent, thus imposing all risk on the agent. With LL, however, the first-best contract is no longer feasible. We contribute to this literature by studying the effect of LL on the shape on the contract when the agent is risk-averse and outcome is not contractible. Sherstyuk (2000) also studies the shape of the contract when the agent is risk-averse. She characterizes the principal's design of performance standards when the agent's LL is fixed at zero, but where the agent may face a non-monetary punishment due to loss of status and a bruised ego. She finds that the contract classifies performance into "unsatisfactory", "satisfactory", and "good". The agent suffers a non-monetary punishment upon unsatisfactory performance, receives nothing when his performance is satisfactory, and is rewarded when his performance is good. We, in contrast, vary the LL level and find that the flat intervals are an artifact of the different LL levels.

Our study also contributes to the literature on the Revelation Principle. Arya, Glover, and Sunder (1998) point out that one motivation for earnings management is the piecewise shape of contracts. (Consider for example, Healy [1985].) Yet, since the contract's shape is determined endogenously, it is not clear why the contract is so designed. The Revelation Principal does not apply to RMC because there is no direct communication between principal and agent. However, the Revelation Principal does apply to the agent's report to the principal 
in the TIC, since the principal can commit to how he will use that report and no one else receives that report. Our paper establishes circumstances under which a contract that induces earnings management, RMC, dominates a truth-inducing contract, TIC.

The paper proceeds as follows: Section 1 presents the model. Section 2 characterizes the contracts and compares them to each other. Section 3 summarizes. Proofs are relegated to the Appendix.

\section{The Model}

The firm is a contract between a risk-neutral principal (investors) and a risk-averse, workaverse agent (management). The latter exerts unobservable effort, $a$, which together with nature generate an economic outcome, $x, x \in X, X=\left\{x_{1}, x_{2}, \ldots, x_{N}\right\}$, where $x_{i}<x_{i+1}, 1 \leq i<i+1 \leq N .5$ The agent alone observes $\mathrm{x}$ before privately and confidentially communicating a message about $\mathrm{x}$ to an auditor, who issues an imperfectly audited, public report to the principal, $\mathrm{r}$, $\mathrm{r} \in \mathrm{R}$, where $\mathrm{R}=X$ is the set of possible reports by the auditor. ${ }^{6}$

The principal designs the agent's incentive contract, $T$, where each payment, denoted by $t$, $t \in T$, is bounded from below by the limited liability (LL) level of the agent, $\ell, T: \mathrm{R} \rightarrow[\ell, \infty){ }^{7}$ Since LL arises from a variety of causes, such as bankruptcy constraints, ${ }^{8}$ minimum wage regulations, and custom, it can either restrict penalties paid by the agent, $\ell<0$, or requires the

\footnotetext{
${ }^{5}$ In what follows, decision variables/functions are italicized.

${ }^{6}$ We employ a single-agent, one-dimensional effort, principal-agent model. For multi-tasking models, consult e.g., Feltham and Xie (1994); and for multi-tasking, multi-agent models, see Feltham and Hofmann (2005) and the citations therein. Restricting analysis to a single-dimension setting is equivalent to assuming that earnings management consumes a negligible amount of the effort of the manager that could otherwise be directed for production-investment decisions. Since, realistically, earnings management requires the cooperation of agents, extending the analysis to a multi-agent model is likely to strengthen our results when the principal cannot enforce a full-commitment regime whereby every agent commits not to collude at the principal's expense.

${ }^{7} t$ is the amount paid by the principal to the agent. A Negative $t$ refers to a payment of $-\mathrm{t}$ from the agent to principal.

${ }^{8}$ We use to LL as a code for any restriction that places a lower bound on payment to the agent. The case in which $\ell=0$ characterizes the bankruptcy constraint that the agent does not pay the principal from private funds (see, e.g., Matthew [2001, p.1).
} 
principal to make a minimum payment to the agent, $\ell \geq 0$. We assume that $\ell \in\left(-\infty, \ell^{\max }\right)$, where $\ell \rightarrow-\infty$ captures the no LL case, and $\ell^{\max }$ is the highest LL level that still leaves such surplus for the principal as would make him willing to contract.

The principal maximizes his expected residual share, $\mathrm{x}-t(\mathrm{r})$; the agent maximizes his expected utility over compensation, $t$, and effort, $a, \mathrm{U}(t, a)$. We adopt the common assumption that the risk-averse, work-averse agent's payoff is separable in monetary transfer and effort, $\mathrm{U}(t, a)=\mathrm{U}(t)-\mathrm{V}(a)$, where $\mathrm{U}^{\prime}>0, \mathrm{U}^{\prime \prime}<0, \mathrm{~V}^{\prime}>0$ and $\mathrm{V}^{\prime \prime}>0$. The agent can obtain a reservation utility level of $\mathrm{U}_{0}$ with alternative employment. ${ }^{9}$

The time-line of the main events is depicted in Figure 1.

Insert Figure 1 about here.

Note that the Date-7 reimbursement to the principal is made long after the agent quits, so that the principal's knowledge of $\mathrm{x}$ at that time cannot be used to induce the agent to reveal the outcome in a timely fashion on Date 4.

\section{$\underline{\text { Assumptions }}$}

A1: The agent chooses between a poor-performance effort, $a_{\mathrm{p}}$, and a good-performance effort, $a_{\mathrm{g}}, a \in\left\{a_{\mathrm{p}}, a_{\mathrm{g}}\right\}$, where $a_{\mathrm{p}}<a_{\mathrm{g}}$. Having a binary choice set entails little loss of generality, since "much of the general insights from studying hidden action models can be conveyed in the simplest setting, where the agent has only two actions to choose from" (Hart and Holmstrom, 1985, p. 79)

We make the following common assumptions:

(i) $\frac{\operatorname{Prob}\left(\mathrm{x}_{\mathrm{i}} \mid a_{\mathrm{g}}\right)}{\operatorname{Prob}\left(\mathrm{x}_{\mathrm{i}} \mid a_{\mathrm{p}}\right)}$ is a strictly increasing function of $\mathrm{i}$.

\footnotetext{
${ }^{9}$ Our assumption that $\ell$ and $\mathrm{U}_{0}$ are independent parameters is innocuous because we compare the alternative contracts across the same parameters.
} 
This is the well-known strict Monotone Likelihood-Ratio Condition (MLRC) (see Rogerson [1985] and Matthews [2001]). A higher outcome is a more convincing signal that the agent chose the good-performance effort level. Like Matthews (2001), we adopt this assumption in the strictly increasing version. Our motivation is to ensure that flat regions in the compensation schedules are not driven by the technology.

(ii) The principal always prefers the good-performance effort.

The principal prefers to bear the cost of incentives rather than forgo the expected benefit of a good-performance effort, $a_{\mathrm{g}}$. Hence, a flat-wage contract is never optimal.

A2: We denote the agent's disclosure strategy by $D_{\mathrm{m}}, D_{\mathrm{m}}: \mathrm{X} \rightarrow \mathrm{X}$. By the one-sided monitoring technology of Schwartz (1997) and Ronen and Yaari (2002), the truth is verified perfectly. Misrepresentation within the range accorded by reporting flexibility is detected with probability $\pi, 1 / 2<\pi<1,{ }^{10}$ while misrepresentation beyond the range accorded by reporting flexibility is always detected. The reporting flexibility parameter that determines the maximum absolute bias that is stochastically feasible is denoted by $\mathrm{q}$, $1 \leq \mathrm{q} \leq \mathrm{N}-1 .{ }^{11}$ The combined effect of audit detection probability and reporting flexibility is such that when the truth is $\mathrm{x}_{\mathrm{i}}$, the firm either reports the truth, $\mathrm{r}=\mathrm{x}_{\mathrm{i}}$, or misrepresents, $\mathrm{r}=\mathrm{x}_{\mathrm{j}}, \mathrm{j} \neq \mathrm{i}$, with the following probabilities:

$$
\begin{aligned}
& \operatorname{Prob}\left[\mathrm{r}=\mathrm{x}_{\mathrm{i}} \mid \mathrm{x}=\mathrm{x}_{\mathrm{i}}, D_{\mathrm{m}}\left(\mathrm{x}_{\mathrm{i}}\right)=\mathrm{x}_{\mathrm{j}}\right]= \begin{cases}1 & \text { if } \mathrm{j}=\mathrm{i} \text { or }|\mathrm{j}-\mathrm{i}|>\mathrm{q}]\} \\
\pi & \text { if } \mathrm{j} \neq \mathrm{i},|\mathrm{j}-\mathrm{i}| \leq \mathrm{q}\},\end{cases} \\
& \operatorname{Prob}\left[\mathrm{r}=\mathrm{x}_{\mathrm{j}} \mid \mathrm{x}=\mathrm{x}_{\mathrm{i}} \neq \mathrm{x}_{\mathrm{j}}, D_{\mathrm{m}}\left(\mathrm{x}_{\mathrm{i}}\right)=\mathrm{x}_{\mathrm{j}}\right]=\left\{\begin{array}{cl}
1-\pi & \text { if }|\mathrm{j}-\mathrm{i}| \leq \mathrm{q} \\
0 & \text { otherwise }
\end{array}\right.
\end{aligned}
$$

\footnotetext{
${ }^{10}$ The independence of the detection probability, $\pi$, of outcome is crucial for our proofs that the contracts are increasing functions of the reports. Without such independence, the comparison between the first-order conditions of two adjacent reports is a meaningless exercise.

${ }^{11}$ For example, if $\mathrm{q}=\mathrm{N}-1$ and the outcome is $\mathrm{x}_{1}$, the agent may successfully pass it off as $\mathrm{x}_{2}$, or, $\mathrm{x}_{3}, \ldots$, up to $\mathrm{x}_{1+\mathrm{q}}=\mathrm{x}_{1+(\mathrm{N}-1)}=\mathrm{x}_{\mathrm{N}}$. However, if $\mathrm{q}=1$, the agent may successfully pass off $\mathrm{x}_{1}$ only as $\mathrm{x}_{2}, \mathrm{x}_{2}$ only as $\mathrm{x}_{3}, \ldots, \mathrm{x}_{\mathrm{N}-1}$ only as $\mathrm{x}_{\mathrm{N}}$.
} 
Similar to Dye (1988) and Evans and Sridhar (1996), our reporting technology allows for report management, but it sets a limit on how large the gap between the truth and the managed report may be. Hence, the report is informative. Dye achieves this combination of credibility and flexibility to manage earnings by assuming that not telling the truth imposes a cost on the agent that increases in the degree of misrepresentation. In our model, there is no cost; the gap between the truth and the communicated outcome is determined by the reporting flexibility parameter, $\mathrm{q}$.

In Evans and Sridhar (1996), the agent's flexibility in reporting an outcome to the principal that is different from the truth is a random variable, determined by the financial reporting system and observed by the agent alone. The report is still informative because it is known that with some positive probability the agent has no flexibility at all so that the report must be truthful. This is equivalent, in our framework, to assuming that $\mathrm{q}$ is a random variable and, with some positive probability, $\mathrm{q}=0$. In our model, $\mathrm{q}$ is deterministic. We achieve the combination of imperfect credibility and report-management flexibility by assuming that the report is imperfectly audited: $\pi>1 / 2$ lends credibility, while $\pi<1$ and $\mathrm{q} \geq 0$ lend a measure of flexibility.

\section{Analysis}

\subsection{The Report-Management-Inducing Contract (RMC)}

In this section, we characterize the contract that is based on the public report, $r$ - the report-management-inducing contract (RMC). We denote it by $C$ (i.e., $T=C$ ), with a generic element $c_{\mathrm{i}}$. That is, $C(r)=\left\{c\left(\mathrm{x}_{\mathrm{k}}\right)\right\}_{\mathrm{k}=1}^{\mathrm{N}}$. 
We solve the game backwards. The last move is made by the agent who, after observing outcome $\mathrm{x}_{\mathrm{i}}, \mathrm{x}=\mathrm{x}_{\mathrm{i}}$, chooses the disclosure to the auditor: ${ }^{12}$

$$
\begin{aligned}
& \forall \mathrm{i}, \mathrm{k}, 1 \leq \mathrm{i} \leq \mathrm{N}, 1 \leq \mathrm{i}-\mathrm{q} \leq \mathrm{k} \leq \mathrm{i}+\mathrm{q} \leq \mathrm{N}, \\
& D_{\mathrm{m}}\left(\mathrm{x}_{\mathrm{i}}\right)=\mathrm{x}_{\mathrm{j}} \text { if: } \\
& \pi \mathrm{U}\left(c\left(\mathrm{x}_{\mathrm{i}}\right)\right)+(1-\pi) \mathrm{U}\left(c\left(D_{\mathrm{m}}\left(\mathrm{x}_{\mathrm{i}}\right)\right)\right) \geq \pi \mathrm{U}\left(c\left(\mathrm{x}_{\mathrm{i}}\right)\right)+(1-\pi) \mathrm{U}\left(c\left(\mathrm{x}_{\mathrm{k}}\right)\right),
\end{aligned}
$$

The agent chooses the report that maximizes his expected payoff; we refer to this report as the target report. ${ }^{13}$ The final report is either the truth, $j=i$, in which case the agent collects $c_{\mathrm{i}}$ for sure, or an undetected misrepresentation, $\mathrm{j} \neq \mathrm{i}$.

Next, the agent chooses effort, which, by our assumption A1(ii), is the good-performance effort, $a=a_{\mathrm{g}}$. By (1),

$$
\begin{gathered}
\sum_{\mathrm{i}=1}^{\mathrm{N}} \operatorname{Prob}\left[\mathrm{x}_{\mathrm{i}} \mid a_{\mathrm{g}}\right]\left\{\pi \mathrm{U}\left(c\left(\mathrm{x}_{\mathrm{i}}\right)\right)+(1-\pi) \mathrm{U}\left(c\left(D_{\mathrm{m}}\left(\mathrm{x}_{\mathrm{i}}\right)\right)\right)\right\}-\mathrm{V}\left(a_{\mathrm{g}}\right) \geq \\
\sum_{\mathrm{i}=1}^{\mathrm{N}} \operatorname{Prob}\left[\mathrm{x}_{\mathrm{i}} \mid a_{\mathrm{p}}\right]\left\{\pi \mathrm{U}\left(c\left(\mathrm{x}_{\mathrm{i}}\right)\right)+(1-\pi) \mathrm{U}\left(c\left(D_{\mathrm{m}}\left(\mathrm{x}_{\mathrm{i}}\right)\right)\right)\right\}-\mathrm{V}\left(a_{\mathrm{p}}\right) .
\end{gathered}
$$

The agent's expected utility from exerting the good-performance effort is at least as high as his expected utility from exerting the poor-performance effort.

Finally, we solve for the equilibrium contract by rearranging (1) and (2) and substituting them into the principal's program. The equilibrium contract is the solution of the following optimization program: ${ }^{14}$

\footnotetext{
${ }^{12}$ We restrict attention to the pure strategy equilibrium. The mixed-strategy equilibrium is given in the working paper version.

${ }^{13}$ Formally: In a RMC, a report, $\mathrm{r}=\mathrm{x}_{\mathrm{j}}$, is a target report for $\mathrm{x}_{\mathrm{i}}$, if $c\left(\mathrm{x}_{\mathrm{j}}\right)=\max \left\{c\left(\mathrm{x}_{\mathrm{k}}\right)\right\}, 1 \leq \mathrm{i}-\mathrm{q} \leq \mathrm{j}, \mathrm{k} \leq \mathrm{i}+\mathrm{q} \leq \mathrm{N}$.

${ }^{14}$ Note that (IC.Dm) is derirved from rearranging (1) .
} 
$\max _{\left\{c\left(\mathrm{x}_{\mathrm{i}}\right)\right\}_{\mathrm{i}=1}^{\mathrm{N}}, D_{\mathrm{m}}} \sum_{\mathrm{i}=1}^{\mathrm{N}} \operatorname{Prob}\left[\mathrm{x}_{\mathrm{i}} \mid a_{\mathrm{g}}\right]\left\{\mathrm{x}_{\mathrm{i}}-\pi c\left(\mathrm{x}_{\mathrm{i}}\right)-(1-\pi) c\left(D_{\mathrm{m}}\left(\mathrm{x}_{\mathrm{i}}\right)\right)\right\}$

s.t.

$\sum_{\mathrm{i}=1}^{\mathrm{N}} \operatorname{Prob}\left[\mathrm{x}_{\mathrm{i}} \mid a_{\mathrm{g}}\right]\left\{\pi \mathrm{U}\left(c\left(\mathrm{x}_{\mathrm{i}}\right)\right)+(1-\pi) \mathrm{U}\left(c\left(D_{\mathrm{m}}\left(\mathrm{x}_{\mathrm{i}}\right)\right)\right)\right\}-\mathrm{V}\left(a_{\mathrm{g}}\right) \geq \mathrm{U}_{0}$.

$\sum_{\mathrm{i}=1}^{\mathrm{N}}\left[\operatorname{Prob}\left[\mathrm{x}_{\mathrm{i}} \mid a_{\mathrm{g}}\right]-\operatorname{Prob}\left[\mathrm{x}_{\mathrm{i}} \mid a_{\mathrm{p}}\right]\left\{\pi \mathrm{U}\left(c\left(\mathrm{x}_{\mathrm{i}}\right)\right)+(1-\pi) \mathrm{U}\left(c\left(D_{\mathrm{m}}\left(\mathrm{x}_{\mathrm{i}}\right)\right)\right)\right\} \geq \mathrm{V}\left(a_{\mathrm{g}}\right)-\mathrm{V}\left(a_{\mathrm{p}}\right)\right.$.

$\forall \mathrm{i}, \mathrm{k} \quad 1 \leq \mathrm{i}-\mathrm{q} \leq \mathrm{j}, \mathrm{k} \leq \mathrm{i}+\mathrm{q} \leq \mathrm{N}, \mathrm{U}\left(c\left(D_{\mathrm{m}}\left(\mathrm{x}_{\mathrm{i}}\right)=\mathrm{x}_{\mathrm{j}}\right)\right) \geq \mathrm{U}\left(c\left(\mathrm{x}_{\mathrm{k}}\right)\right)$.

$\forall \mathrm{i}, \mathrm{i}=1,2, \ldots, \mathrm{N}, \quad c\left(\mathrm{x}_{\mathrm{i}}\right) \geq \ell$.

Note that unless the agent reports the truth, $D_{\mathrm{m}}\left(\mathrm{x}_{\mathrm{i}}\right)=\mathrm{x}_{\mathrm{i}}$, or chooses a "big lie," $D_{\mathrm{m}}\left(\mathrm{x}_{\mathrm{i}}\right)=\mathrm{x}_{\mathrm{j}},|\mathrm{j}-\mathrm{i}|>q$, the agent's compensation given the realized outcome is $\mathrm{x}_{\mathrm{i}}$ is a gamble between the payment upon successful misrepresentation (with probability of $1-\pi$ ) and payment upon truth telling (with probability $\pi$ ).

Denote by (IC. $\left.D_{\mathrm{mji}}\right)$ and (IC. $\left.D_{\mathrm{mki}}\right)$ the disclosure constraints when the target report for $x_{j}$ is $x_{i}, D_{m}\left(x_{j}\right)=x_{i}$, and the target report for $x_{k}$ is different from the feasible $x_{i}, D_{m}\left(x_{k}\right) \neq x_{i}$, $|\mathrm{i}-\mathrm{k}|<\mathrm{q}, \mathrm{i} \neq \mathrm{k}$, respectively. Denote by $\lambda^{\mathrm{C}}, \mu^{\mathrm{C}}, \eta_{\mathrm{ji}}^{C}, \eta_{\mathrm{ki}}^{C}$, and $\delta_{\mathrm{i}}^{C}$, the Lagrange multipliers of (PC), (IC. $a),\left(\mathrm{IC} . D_{\mathrm{mji}}\right),\left(\mathrm{IC} . D_{\mathrm{mki}}\right)$, and $\left(\mathrm{LC}_{\mathrm{i}}\right)$, respectively. The solution yields the following $\mathrm{N}$ equilibrium conditions: 


$$
\begin{array}{r}
\forall \mathrm{i}, \mathrm{i}=1,2, \ldots, \mathrm{N}, \frac{1}{\mathrm{U}^{\prime}\left(c\left(\mathrm{x}_{\mathrm{i}}\right)\right)}=\lambda^{C}+\mu^{C}\left[1-\frac{\operatorname{Prob}\left[\mathrm{r}=\mathrm{x}_{\mathrm{i}} \mid a_{g}\right]}{\operatorname{Prob}\left[\mathrm{r}=\mathrm{x}_{\mathrm{i}} \mid a_{p}\right]}\right]+ \\
\frac{\sum_{\mathrm{j}, 1 \leq \mathrm{i}-\mathrm{q} \leq \mathrm{j} \leq \mathrm{i}+\mathrm{q} \leq \mathrm{N}} \eta_{\mathrm{ji}}^{C}-\sum_{\mathrm{k}, 1 \leq \mathrm{i}-\mathrm{q} \leq \mathrm{k} \leq \mathrm{i}+\mathrm{q} \leq \mathrm{N}} \eta_{\mathrm{ki}}^{C}+\delta_{\mathrm{i}}^{C}}{\operatorname{Prob}\left[\mathrm{r}=\mathrm{x}_{\mathrm{i}} \mid a_{g}\right]},
\end{array}
$$

where $\operatorname{Prob}\left[\mathrm{r}=\mathrm{x}_{\mathrm{i}} \mid a\right]=\pi \operatorname{Prob}\left[\mathrm{x}_{\mathrm{i}} \mid a_{g}\right]+(1-\pi) \sum_{\mathrm{j}} \operatorname{Prob}\left[\mathrm{x}=\mathrm{x}_{\mathrm{j}} \mid a_{g}, D_{\mathrm{m}}\left(\mathrm{x}_{\mathrm{j}}\right)=\mathrm{x}_{\mathrm{i}}\right]$.

Note that the equilibrium conditions are determined by the probabilities of the reports, which are determined, in turn, by the agent's disclosure strategy.

We now characterize the equilibrium combinations of disclosure strategies and contracts in Proposition 1.

\section{Proposition 1:}

Let either:

(i) $\mathrm{q}=1$, or

(ii) $\mathrm{q}>1$, and the following (MLC) obtains:

$$
\begin{aligned}
& \forall \mathrm{i}, 1 \leq \mathrm{i}-\mathrm{q} \leq \mathrm{i} \leq \mathrm{N}-1, \\
& \frac{\operatorname{Prob}\left[\mathrm{x}=\mathrm{x}_{\mathrm{i}-\mathrm{q}} \mid a_{\mathrm{g}}\right]}{\operatorname{Prob}\left[\mathrm{x}=\mathrm{x}_{\mathrm{i}+1-\mathrm{q}} \mid a_{\mathrm{g}}\right]} \geq \frac{\operatorname{Prob}\left[\mathrm{x}=\mathrm{x}_{\mathrm{i}} \mid a_{\mathrm{g}}\right]}{\operatorname{Prob}\left[\mathrm{x}=\mathrm{x}_{\mathrm{i}+1} \mid a_{\mathrm{g}}\right]},
\end{aligned}
$$

(a) The equilibrium unlimited-liability RMC is a strictly increasing function of the public report, $\mathrm{r}, c^{*}\left(\mathrm{x}_{1}\right)<c^{*}\left(\mathrm{x}_{2}\right)<\ldots<c^{*}\left(\mathrm{x}_{\mathrm{N}}\right)$. The agent inflates the disclosure to the auditor up to the maximum message that might elude detection; i.e., $D_{\mathrm{m}}^{*}\left(\mathrm{x}_{\mathrm{i}}\right)=\mathrm{x}_{\min \{\mathrm{i}+\mathrm{q}, \mathrm{N}\}}$.

(b) The equilibrium LL RMC is a piecewise contract, where below a threshold report, payments are set at the LL level, $\ell$, and above the threshold report, the contract is a strictly increasing schedule. That is, there is a critical $\mathrm{k}$, such that 
$\ell=c^{*}\left(\mathrm{x}_{1}\right)=\ldots=c^{*}\left(\mathrm{x}_{\mathrm{k}}\right)<c^{*}\left(\mathrm{x}_{\mathrm{k}+1}\right)<\ldots<c\left(\mathrm{x}_{\mathrm{N}}\right)^{*} ; \mathrm{k}$ is determined by the number of binding $\left(\mathrm{LC}_{\mathrm{i}}\right)$, and, at most, the first $\mathrm{N}-1$ payments are set to the $\mathrm{LL}$ level, $\ell$., i.e., $1 \leq \mathrm{k} \leq \mathrm{N}-1$. The agent inflates the message (reports the truth) if successful misrepresentation awards him (no) more than the LL-level:

$$
D_{\mathrm{m}}^{*}\left(\mathrm{x}_{\mathrm{i}}\right)=\left\{\begin{array}{ll}
\mathrm{x}_{\min \{i+\mathrm{q}, \mathrm{N}\}} & \text { if } c^{*}\left(\mathrm{x}_{\mathrm{i}}\right)<c^{*}\left(\mathrm{x}_{\min \{i+\mathrm{q}, \mathrm{N}\}}\right) \\
\mathrm{x}_{\mathrm{i}} & \text { if } c^{*}\left(\mathrm{x}_{\min \{\mathrm{i}+\mathrm{q}, \mathrm{N}\}}\right)=\ell
\end{array}\right\} .
$$

Proposition 1 characterizes the equilibrium. The agent discloses the maximum outcome that may elude detection to the auditor, and the principal designs a strictly increasing schedule when LL does not affect the contract. Although a strictly increasing schedule is quite common in the agency literature, note that there is a significant difference between an RMC and a contract based on observed outcomes. By the MLRC, a higher report under the latter contract is good news with respect to effort, but when a contract is based on a report that might be managed, a higher report may not be good news, because the agent may have manipulated the report. That is, although $\frac{\operatorname{Prob}\left[\mathrm{x}_{\mathrm{i}} \mid a_{\mathrm{g}}\right]}{\operatorname{Prob}\left[\mathrm{x}_{\mathrm{i}} \mid a_{\mathrm{p}}\right]}$ is a monotone increasing function of $\mathrm{i}$, $\frac{\operatorname{Prob}\left[\mathrm{r}=\mathrm{x}_{\mathrm{k}} \mid a_{\mathrm{g}}, D_{\mathrm{m}}^{*}\right]}{\operatorname{Prob}\left[\mathrm{r}=\mathrm{x}_{\mathrm{k}} \mid a_{\mathrm{p}}, D_{\mathrm{m}}^{*}\right]}$ may not be. Hence, RMC is a strictly increasing schedule when the technology preserves the same ordering of the reports as the MLRC's ordering on outcomes, so that higher reports are better news on effort than lower reports. We identify two such conditions. One is that flexibility is small, $\mathrm{q}=1$ (a necessary and sufficient condition). The other is that the technology is concave, so that the higher the outcome, the lower the impact that the noise in the report that arises from earnings management has on the relative probabilities of consecutive reports. 
When the contract is an increasing function, the agent inflates the report. He either reports the maximum feasible report given flexibility $\mathrm{q}, D_{\mathrm{m}}^{*}\left(\mathrm{x}_{\mathrm{i}}\right)=\mathrm{x}_{\mathrm{i}+\mathrm{q}}$ or the maximum report, $D_{\mathrm{m}}^{*}\left(\mathrm{x}_{\mathrm{i}}\right)=\mathrm{x}_{\mathrm{N}}$ if $\mathrm{i}+\mathrm{q} \geq \mathrm{N}$.

Even if $\mathrm{q}=1$ or $\mathrm{q}>1$ and the (MLC) obtains, LL, which guarantees that no payment is lower than $\ell$, flattens the contract and thus prevents it from being a strictly increasing function. An RMC might induce costless truth-telling locally for one or more outcomes contained in any flat region that ranges over at least $q+1$ outcomes. ${ }^{15}$ Note that at most only $\mathrm{N}-1$ payments can be set to the LL level, because by assumption A1(ii) a flat wage contract could not be an equilibrium.

Figure 2 depicts the equilibrium in a five-outcome setting with $\mathrm{q}=1$ when $\left(\mathrm{LC}_{\mathrm{i}}\right)$ are binding for the three lowest payments, $\mathrm{i}=1,2,3$. For shorthand, $c^{*}\left(\mathrm{x}_{\mathrm{i}}\right)=c_{\mathrm{i}}$.

Insert Figure 2 about here.

When MLR does not obtain, the game does not have a pure strategy. See details in our working paper.

\subsection{The Truth-Inducing Contract (TIC)}

In this section, we characterize a contract that induces truth-telling. An immediate candidate is a contract based on $r$ alone that induces the agent to make a truthful disclosure to the auditor. However, a contract that provides incentives both to exert the good-performance effort and to disclose the truth does not exist. ${ }^{16}$ To find a truth-inducing contract we invoke

15 For example, observe that when $\mathrm{x}=\mathrm{x}_{1}, D_{\mathrm{m}}\left(\mathrm{x}_{1}\right)=\mathrm{x}_{1+\mathrm{q}}$, since both $\mathrm{x}_{1}$ and $\mathrm{x}_{1+\mathrm{q}}$ are contained in the flat region, the agent is not paid more by inflating his report.

${ }^{16}$ Formally, a contract based on $\mathrm{r}$ alone that induces truthful disclosure to the auditor satisfies the (IC. $D_{\mathrm{m}}$ ) constraints that state that truthful disclosure is preferable to disclosing some target outcome. Consider (IC. $D_{\mathrm{m}}$ ) for two outcomes, $i$ and $j$, such that $|j-i| \leq|q|, j \neq i$. 
the Revelation Principle, by which there is no loss of generality in restricting analysis to an incentive-compatible contract. The appeal to the Revelation Principle implies augmenting the game with a communication phase between the principal and the agent (see Myerson [1991]). ${ }^{17}$ We denote the agent's strategy of disclosure to the principal by $D_{\mathrm{p}}, D_{\mathrm{p}}: \mathrm{X} \rightarrow \mathrm{X}$, assuming that this disclosure is made after the agent has observed the outcome (on Date 3 ) but before the agent provides a report to the auditor (on Date 4). Consequently, under a truthinducing contract (TIC), the principal receives two signals: direct disclosure from the agent and an imperfect report from the auditor. Furthermore, by the Revelation Principle, the principal designs a contract, $S$, that induces the agent to report the truth, $D_{\mathrm{p}}(\mathrm{x})=\mathrm{x}$.

In what follows, we denote the TIC by $S$ with a generic element by $s\left(\mathrm{x}_{\mathrm{i}}, \mathrm{x}_{\mathrm{j}}\right)$, where $\mathrm{i}$ and $\mathrm{j}$ index the disclosure of $\mathrm{x}_{\mathrm{i}}$ to the principal, $D_{\mathrm{p}}\left(\mathrm{x}_{\mathrm{i}}\right)=\mathrm{x}_{\mathrm{i}}$, and the audited report of $\mathrm{x}_{\mathrm{j}}, \mathrm{r}=\mathrm{x}_{\mathrm{j}}$, respectively, $S=\left\{s\left(\mathrm{x}_{\mathrm{i}}, \mathrm{x}_{\mathrm{j}}\right)\right\}_{\mathrm{i}, \mathrm{j}=1}^{\mathrm{N}}$. In the following, we skip the details of the agent's decisions, which are similar to those discussed above for an RMC. Under truth-revelation, and by our assumption that the principal prefers to induce the agent to exert the good-performance effort, $a_{\mathrm{g}}$, the principal designs $S\left(D_{\mathrm{p}}, \mathrm{r}\right)$ that solves the following program:

$$
\begin{array}{lll}
\text { If } \quad \mathrm{x}=\mathrm{x}_{\mathrm{i}}, & \mathrm{U}\left(c\left(\mathrm{x}_{\mathrm{i}}\right)\right) \geq \pi \mathrm{U}\left(c\left(\mathrm{x}_{\mathrm{i}}\right)\right)+(1-\pi) \mathrm{U}\left(c\left(\mathrm{x}_{\mathrm{j}}\right)\right) . & \left(\text { IC } . D_{\text {mij }}\right) \\
\text { If } \quad \mathrm{x}=\mathrm{x}_{\mathrm{j}}, & \mathrm{U}\left(c\left(\mathrm{x}_{\mathrm{j}}\right)\right) \geq \pi \mathrm{U}\left(c\left(\mathrm{x}_{\mathrm{j}}\right)\right)+(1-\pi) \mathrm{U}\left(c\left(\mathrm{x}_{\mathrm{i}}\right)\right) .
\end{array}
$$

Rearranging yields a set of two equations: $\mathrm{U}\left(c\left(\mathrm{x}_{\mathrm{i}}\right)\right) \geq \mathrm{U}\left(c\left(\mathrm{x}_{\mathrm{j}}\right)\right)$ and $\mathrm{U}\left(c\left(\mathrm{x}_{\mathrm{i}}\right)\right) \leq \mathrm{U}\left(c\left(\mathrm{x}_{\mathrm{j}}\right)\right)$. Clearly, these equations must hold as a strict equality; i.e., $c\left(\mathrm{x}_{\mathrm{i}}\right)=c\left(\mathrm{x}_{\mathrm{j}}\right)$. Since this equality holds for any pair of $\mathrm{i}$ and $\mathrm{j}$ with a distance of $\mathrm{q}$ between them, it holds globally. A flat wage contract violates A1(ii).

${ }^{17}$ Myerson [1991]:

\footnotetext{
It may be natural to ask why we have been focusing our attention on mediated communication systems in which it is rational for all players to obey the mediator. The reason for this focus is that such communication systems can simulate any equilibrium of any game that can be generated from any given strategic-form game by adding any communication system. (p. 255; emphasis added)
} 


$$
\begin{aligned}
& \max _{\left\{S, D_{\mathrm{m}}, D_{\mathrm{p}}\right\}} \mathrm{E}\left[\mathrm{x}-S\left(D_{\mathrm{p}}, \mathrm{r}\right) \mid a_{\mathrm{g}}, D_{\mathrm{m}}\right] \\
& \text { s.t. } \\
& \mathrm{E}\left[\mathrm{U}\left(S\left(D_{\mathrm{p}}, \mathrm{r}\right)\right) \mid a_{\mathrm{g}}, D_{\mathrm{m}}\right]-\mathrm{V}\left(a_{\mathrm{g}}\right) \geq \mathrm{U}_{0} . \\
& a_{g} \in \underset{a \in\left\{a_{\mathrm{p}}, a_{\mathrm{g}}\right\}}{\arg \max \mathrm{E}}\left[\mathrm{U}\left(S\left(D_{\mathrm{p}}, \mathrm{r}\right)\right) \mid a, D_{\mathrm{m}}\right]-\mathrm{V}(a) . \\
& \forall \mathrm{i}, \mathrm{i}=1,2, \ldots, \mathrm{N},\left(D_{\mathrm{m}}, D_{\mathrm{p}}\left(\mathrm{x}_{\mathrm{i}}\right)=\mathrm{x}_{\mathrm{i}}\right) \in \underset{D_{\mathrm{p}}\left(\mathrm{x}_{\mathrm{i}}\right) \in \mathrm{X}}{\arg \max } \mathrm{E}\left[\mathrm{U}\left(S\left(D_{\mathrm{p}}\left(\mathrm{x}_{\mathrm{i}}\right), \mathrm{r}\right)\right) \mid \mathrm{x}_{\mathrm{i}}, D_{\mathrm{m}}\left(\mathrm{x}_{\mathrm{i}}\right)\right] \\
& D_{\mathrm{m}}\left(\mathrm{x}_{\mathrm{i}}\right) \in \mathrm{X}
\end{aligned}
$$

$$
\forall \mathrm{i}, \mathrm{j}, \mathrm{i}, \mathrm{j}=1,2, \ldots, \mathrm{N}, s_{\mathrm{ij}}=S\left(\mathrm{x}_{\mathrm{i}}, \mathrm{x}_{\mathrm{j}}\right) \geq \ell .
$$

The principal maximizes his expected payoff subject to the contract guaranteeing the agent his reservation utility so that he is willing to participate in the contract (PC). The contract provides the agent with incentives to exert the good-performance effort (IC.a) and to make disclosures to the auditor (IC. $\left.D_{\mathrm{m}}\right)$ and to the principal (IC. $D_{\mathrm{p}}$ ), and no payment can be lower than the LL level (LC).

An examination of the principal's program reveals an indeterminacy regarding the disclosure to the auditor. Although the Revelation Principle prescribes that the message sent to the principal be truthful (since the agent's message choice has no "real" effects and the principal controls how the message influences the agent's compensation), it does not make the same prescription for the disclosure made by the agent to the auditor. The outcome of this disclosure depends on the monitoring technology, and it is not contractible, i.e., the principal cannot commit to how the auditor will respond to the agent's reported outcome. The Revelation Principle prescribes, however, that the principal gives the agent instructions on what to disclose to the auditor and, through the design of the contract, provides the agent with incentives to follow the instructions. What will the principal's instructions be? 


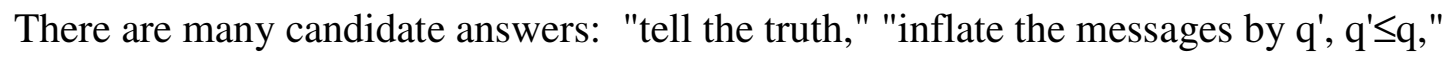
"smooth by inflating high outcomes and deflating low outcomes," and so on. One thing is clear: the instruction will ensure that the audited report is informative, in that it can be used to auditor the message to the principal. For example, suppose that the agent reports the truth to the principal and is instructed to inflate the disclosure to the auditor by one outcome; i.e., $D_{\mathrm{m}}\left(\mathrm{x}_{\mathrm{i}}\right)=\mathrm{x}_{\min \{\mathrm{i}+1, \mathrm{~N}\}}$. If the principal observes a message of $\mathrm{x}_{\mathrm{i}}$ and an audited report of $\mathrm{x}_{\mathrm{i}}$, or a message of $x_{i}$ and an audited report of $x_{i+1}$, he pays the agent the amount corresponding to $x_{i}$. Any other message triggers a penalty. The agent is deterred from communicating $\mathrm{x}_{\mathrm{i}+2}$ to the auditor, $D_{\mathrm{m}}\left(\mathrm{x}_{\mathrm{i}}\right)=\mathrm{x}_{\mathrm{i}+2}$, by a penalty if $\mathrm{r}=\mathrm{x}_{\mathrm{i}+2}$, which can occur with probability of $1-\pi$.

In what follows, we solve the principal's program, assuming that the agent discloses the truth to the auditor, and then in Proposition 2 we prove that such a strategy is an equilibrium. We claim that there is no loss of generality in assuming that the principal instructs the agent to disclose the truth to the auditor, as any contract with (truth-revealing) external report management $(\mathrm{r} \neq \mathrm{x})$ and internal truth-telling $\left(D_{\mathrm{p}}(\mathrm{x})=\mathrm{x}\right)$ yields the same payoffs as the one with no earnings management. ${ }^{18}$

The other side of the coin of the fact that a truthful disclosure entails no loss of generality is that there are also equilibria with external earnings management—combining a false disclosure to the auditor with a truthful disclosure to the principal. Thus there appears to be yet another answer to our research question: "If earnings management is harmful to shareholders, why don't they design contracts that induce managers to reveal the truth?" Shareholders indeed may not consider earnings management to be harmful (see, e.g., the

18 To see this point, compare two disclosure strategies:

$$
\begin{aligned}
& \text { If } D_{\mathrm{m}}\left(\mathrm{x}_{\mathrm{i}}\right)=\mathrm{x}_{\mathrm{i}}, \mathrm{U}\left(s\left(\mathrm{x}_{\mathrm{i}}, \mathrm{x}_{\mathrm{i}}\right)\right) \geq(1-\pi) \mathrm{U}\left(s\left(\mathrm{x}_{\mathrm{j}}, \mathrm{x}_{\mathrm{s}}\right)\right)+\pi \mathrm{U}(\ell), \\
& \begin{array}{r}
\mathrm{j}, \mathrm{s},=1,2, \ldots, \mathrm{N}, \mathrm{s} \neq \mathrm{i} . \\
\text { If } D_{\mathrm{m}}\left(\mathrm{x}_{\mathrm{i}}\right)=\mathrm{x}_{\mathrm{k}}, \mathrm{x}_{\mathrm{k}} \neq \mathrm{x}_{\mathrm{i}}, \pi \mathrm{U}\left(s\left(\mathrm{x}_{\mathrm{i}}, \mathrm{x}_{\mathrm{i}}\right)\right)+(1-\pi) \mathrm{U}\left(s\left(\mathrm{x}_{\mathrm{i}}, \mathrm{x}_{\mathrm{k}}\right)\right) \geq \\
(1-\pi) \mathrm{U}\left(s\left(\mathrm{x}_{\mathrm{j}}, \mathrm{x}_{\mathrm{s}}\right)\right)+\pi \mathrm{U}(\ell), \mathrm{j}, \mathrm{s},=1,2, \ldots, \mathrm{N}, \mathrm{s} \neq \mathrm{k} .
\end{array}
\end{aligned}
$$

Since the argument on the left-hand side of the second equation represents the disclosure when the agent follows the principal's instructions, there is no difference between the first and second equations when $s\left(\mathrm{x}_{\mathrm{i}}, \mathrm{X}_{\mathrm{k}}\right)=s\left(\mathrm{x}_{\mathrm{i}}, \mathrm{X}_{\mathrm{i}}\right)$. By the informativeness criterion of Holmstrom (1979), and by virtue of the fact that $r=x_{k}$ is as informative as a report of $\mathrm{r}=\mathrm{X}_{\mathrm{i}}$, it can be shown that the equality of $s\left(\mathrm{x}_{\mathrm{i}}, \mathrm{X}_{\mathrm{k}}\right)=s\left(\mathrm{X}_{\mathrm{i}}, \mathrm{X}_{\mathrm{i}}\right)$ obtains from the first-order conditions of the principal's program. 
price-maximizing owners in Ronen and Yaari [2002]), and they can have both external earnings management and internal truth-telling if they so wish.

To solve the program, we reintroduce the concept of a target report.

DEFINITION 1: In a TIC, a report $\mathrm{r}=\mathrm{x}_{\mathrm{j}}$ is a target report for $\mathrm{x}_{\mathrm{i}}$ if $s\left(\mathrm{x}_{\mathrm{j}}, \mathrm{X}_{\mathrm{j}}\right)=\max \left\{s\left(\mathrm{x}_{\mathrm{k}}, \mathrm{x}_{\mathrm{k}}\right)\right\}, 1 \leq \mathrm{i}-\mathrm{q} \leq \mathrm{j}, \mathrm{k} \leq \mathrm{i}+\mathrm{q} \leq \mathrm{N}$.

Target reports are vital to the design of a TIC because the agent is willing to reveal the truth only when truth-telling yields a higher expected payoff than the disclosure of the target report. If the agent attempts to falsely disclose the target report, he faces a gamble: with probability $\pi$, the auditor discovers the truth and the agent is penalized, and with probability of $1-\pi$ the agent succeeds and earns the payoff of the target report. By the Maximum Deterrence Principle (Kofman and Lawarree [1993]), the penalty equals the lowest possible level—the agent's LL level, $\ell$; i.e., $s\left(\mathrm{x}_{\mathrm{j}}, \mathrm{x}_{\mathrm{i}}\right)=\ell$ for every $\mathrm{j}, \mathrm{j} \neq \mathrm{i}$.

We now solve a reduced program that ignores some of the constraints. As Christensen and Feltham (2005) note, when the principal-agent contract requires the agent to take more than one action, there is a hierarchy of constraints, in that the "single" shirking constraints require that the agent does not deviate from the equilibrium in a choice of one action only, the "double" shirking constraints require that the agent does not deviate from the equilibrium in two actions only, and so on. Since in our setting the agent takes three actions-effort, disclosure to the auditor, and disclosure to the principal, the principal's program contains three levels of constraints. We solve a reduced program with "single" shirking constraints only, as its solution satisfies the double/triple-shirking constraints. ${ }^{19}$ As discussed above, we substitute $D_{\mathrm{m}}(\mathrm{x})=\mathrm{x}$ as well, relegating the proof that the solution of the reduced program satisfies (IC. $D_{\mathrm{m}}$ ) to Proposition 2, where we show that truthful disclosure to the auditor is indeed the agent's best response to the contract.

${ }^{19}$ The (long and tedious) proof of this statement is available upon request from the authors. 
A TIC then solves the following reduced program: ${ }^{20}$

$$
\max _{\left\{s\left(\mathrm{x}_{\mathrm{i}}, \mathrm{x}_{\mathrm{i}}\right)\right\}_{\mathrm{i}=1}^{\mathrm{N}}, D_{\mathrm{p}}} \sum_{\mathrm{i}=1}^{\mathrm{N}} \operatorname{Prob}\left(\mathrm{x}_{\mathrm{i}} \mid a_{\mathrm{g}}\right)\left(\mathrm{x}_{\mathrm{i}}-s\left(\mathrm{x}_{\mathrm{i}}, \mathrm{x}_{\mathrm{i}}\right)\right)
$$

s.t.

$$
\begin{aligned}
& \sum_{\mathrm{i}=1}^{\mathrm{N}} \operatorname{Prob}\left(\mathrm{x}_{\mathrm{i}} \mid a_{\mathrm{g}}\right) \mathrm{U}\left(s\left(\mathrm{x}_{\mathrm{i}}, \mathrm{x}_{\mathrm{i}}\right)\right)-\mathrm{V}\left(a_{\mathrm{g}}\right) \geq \mathrm{U}_{0} . \\
& \sum_{\mathrm{i}=1}^{\mathrm{N}} \operatorname{Prob}\left(\mathrm{x}_{\mathrm{i}} \mid a_{\mathrm{g}}\right) \mathrm{U}\left(s\left(\mathrm{x}_{\mathrm{i}}, \mathrm{x}_{\mathrm{i}}\right)\right)-\mathrm{V}\left(a_{\mathrm{g}}\right) \geq \sum_{\mathrm{i}=1}^{\mathrm{N}} \operatorname{Prob}\left(\mathrm{x}_{\mathrm{i}} \mid a_{\mathrm{p}}\right) \mathrm{U}\left(s\left(\mathrm{x}_{\mathrm{i}}, \mathrm{x}_{\mathrm{i}}\right)\right)-\mathrm{V}\left(a_{\mathrm{p}}\right) .
\end{aligned}
$$

$$
\begin{aligned}
& \forall \mathrm{i}, \mathrm{j}, \quad \mathrm{i}=1,2, \ldots, \mathrm{N}, \quad 1 \leq \mathrm{i}-\mathrm{q} \leq \mathrm{j} \leq \mathrm{N}, \\
& \mathrm{U}\left(s\left(\mathrm{x}_{\mathrm{i}}, \mathrm{x}_{\mathrm{i}}\right)\right) \geq \pi \mathrm{U}(\ell)+(1-\pi) \mathrm{U}\left(s\left(\mathrm{x}_{\mathrm{j}}, \mathrm{x}_{\mathrm{j}}\right)\right) .
\end{aligned}
$$

$\forall \mathrm{i}, \quad \mathrm{i}=1,2, \ldots, \mathrm{N}, \quad s\left(\mathrm{x}_{\mathrm{i}}, \mathrm{x}_{\mathrm{i}}\right) \geq \ell$.

Denote by $\left(\mathrm{TC}_{\mathrm{puy}}\right)$ the truth-inducing constraint that deters the agent from disclosing $\mathrm{x}_{\mathrm{y}}$ to the principal when the outcome is $\mathrm{x}_{\mathrm{u}}$, and; upon adopting similar notation ${ }^{21}$ to that of the RMC's program denote by $\lambda^{\mathrm{S}}, \mu^{\mathrm{S}}, \rho_{\mathrm{ij}}^{\mathrm{S}}, \rho_{\mathrm{ki}}^{S}$, and $\delta_{\mathrm{i}}^{S}$, the Lagrange multipliers of (PC), (IC.a), $\left(\mathrm{TC}_{\mathrm{ij}}\right),\left(\mathrm{TC}_{\mathrm{ki}},\right)$, and $\left(\mathrm{LC}_{\mathrm{i}}\right)$ respectively. The solution yields the following $\mathrm{N}$ equilibrium conditions:

$$
\forall \mathrm{i}, \mathrm{i}=1,2, \ldots, \mathrm{N}, \quad \frac{1}{\mathrm{U}^{\prime}\left(s\left(\mathrm{x}_{\mathrm{i}}, \mathrm{x}_{\mathrm{i}}\right)\right)}=\lambda^{S}+\mu^{S}\left[1-\frac{\operatorname{Prob}\left[\mathrm{x}_{\mathrm{i}} \mid a_{\mathrm{p}}\right]}{\operatorname{Prob}\left[\mathrm{x}_{\mathrm{i}} \mid a_{\mathrm{g}}\right]}\right]+
$$

\footnotetext{
${ }^{20}$ In the solution of this program, it is convenient to work with rearranged (IC):

$\sum_{\mathrm{i}=1}^{\mathrm{N}}\left\{\operatorname{Prob}\left[\mathrm{x}_{\mathrm{i}} \mid a_{\mathrm{g}}\right]-\operatorname{Prob}\left[\mathrm{x}_{\mathrm{i}} \mid a_{\mathrm{p}}\right]\right\} \mathrm{U}\left(s\left(\mathrm{x}_{\mathrm{i}}, \mathrm{x}_{\mathrm{i}}\right) \geq \mathrm{V}\left(a_{\mathrm{g}}\right)-\mathrm{V}\left(a_{\mathrm{p}}\right)\right.$.

${ }^{21}$ Note that, for parsimony, we adopted the notation for (IC. $\left.D_{\mathrm{m}}\right)$ in RMC to $\left(\mathrm{TC}_{\mathrm{ij}}\right)$ in TIC, although the two sets of constraints are different.
} 
$\frac{\sum_{\substack{\mathrm{j} j \leq \mathrm{i}-\mathrm{q} \leq j \leq \mathrm{i}+\mathrm{q} \leq \mathrm{N}, \mathrm{j} \neq \mathrm{i} \\ \mathrm{ijj}}}^{S}-\sum_{\substack{\mathrm{k} \\ 1 \leq \mathrm{i}-\mathrm{q} \leq \mathrm{k} \leq \mathrm{i}+\mathrm{q} \leq \mathrm{N}, \mathrm{k} \neq \mathrm{i}}}(1-\pi) \rho_{\mathrm{ki}}^{S}+\delta_{\mathrm{i}}^{S}}{\operatorname{Prob}\left[\mathrm{x}_{\mathrm{i}} \mid a_{\mathrm{g}}\right]} \cdot{ }^{22}$

LEMMA 1: Every payment along the equilibrium play, $s^{*}\left(\mathrm{x}_{\mathrm{i}}, \mathrm{X}_{\mathrm{i}}\right)$, exceeds the LL level, $\ell$, $\forall \mathrm{i}, s^{*}\left(\mathrm{x}_{\mathrm{i}}, \mathrm{x}_{\mathrm{i}}\right)>\ell$.

Lemma 1 states that the agent is paid in equilibrium more than $\ell$, pointwise. The reason is that $\ell$ constitutes a penalty upon discovery of misrepresentation. Hence, the agent's payoff upon faithfully revealing the truth cannot equal the penalty for not revealing the truth (unless the contract is a flat wage that equals $\ell$, which violates assumption A1(ii)). Lemma 1 facilitates the characterization of $S$, since no $\left(\mathrm{LC}_{\mathrm{i}}\right)$ is binding.

\section{Proposition 2:}

(a) If $\mathrm{q}=1$, or $\mathrm{q}>1$ and at most only one $\left(\mathrm{TC}_{\mathrm{ij}}\right)$ is binding, $1 \leq \mathrm{i} \leq \mathrm{N}-1,1 \leq \mathrm{i}-\mathrm{q} \leq \mathrm{j} \leq \mathrm{i}+\mathrm{q} \leq \mathrm{N}$, TIC is a strictly increasing schedule. That is,

$$
s^{*}\left(\mathrm{X}_{1}, \mathrm{X}_{1}\right)<s^{*}\left(\mathrm{X}_{2}, \mathrm{X}_{2}\right)<\ldots<s^{*}\left(\mathrm{X}_{\mathrm{N}}, \mathrm{X}_{\mathrm{N}}\right) .
$$

(b) If $\mathrm{q}>1$, and at least two $\left(\mathrm{TC}_{\mathrm{ij}}\right)$ are binding, $1 \leq \mathrm{i} \leq \mathrm{N}-1,1 \leq \mathrm{i}-\mathrm{q} \leq \mathrm{j} \leq \mathrm{i}+\mathrm{q} \leq \mathrm{N}$, the TIC contains flat regions. It is a nondecreasing schedule with global maximum at $\mathrm{x}_{\mathrm{N}}$. That is, $s^{*}\left(\mathrm{x}_{1}, \mathrm{X}_{1}\right) \leq s^{*}\left(\mathrm{x}_{2}, \mathrm{x}_{2}\right) \leq \ldots<s^{*}\left(\mathrm{x}_{\mathrm{N}}, \mathrm{X}_{\mathrm{N}}\right)$.

(c) In equilibrium, the agent sends a truthful message to the auditor, $D_{\mathrm{m}}^{*}(\mathrm{x})=\mathrm{x}$.

Proposition 2 characterizes the TIC, the agent's strategy of communicating to the auditor, and the principal's beliefs. As expected from an incentive contract, the schedule of payments increases in the performance measures. The contract is strictly increasing between

\footnotetext{
${ }^{22}$ When $\mathrm{x}_{\mathrm{i}}$ is the potential target report for $\mathrm{x}_{\mathrm{k}}$, then, relative to $\mathrm{k}, \mathrm{i}$ must satisfy that $1 \leq \mathrm{k}-\mathrm{q} \leq \mathrm{i} \leq \mathrm{k}+\mathrm{q} \leq \mathrm{N}$.
} 
$\mathrm{N}-1$ and $\mathrm{N}, s^{*}\left(\mathrm{X}_{\mathrm{N}}, \mathrm{X}_{\mathrm{N}}\right)>s^{*}\left(\mathrm{X}_{\mathrm{N}-1}, \mathrm{X}_{\mathrm{N}-1}\right)$. Since the agent is freely willing to tell the truth when the true outcome earns him the maximum payoff (i.e., $\left.s^{*}\left(\mathrm{x}_{\mathrm{N}}, \mathrm{x}_{\mathrm{N}}\right)\right)$, the payment is determined by the incentives to exert effort, which, by the MLRC condition, yield a local $\operatorname{maximum}$ at $\mathrm{x}_{\mathrm{N}}$.

However, it is a priori unclear when a TIC is a strictly increasing schedule for reports other than $\mathrm{x}_{\mathrm{N}}$. The answer depends on the reporting flexibility, $\mathrm{q}$, and on the LL level, $\ell$. Suppose $\ell$ is sufficiently high such that two different outcomes, $x_{i}$ and $x_{k}$, share the same target report, $\mathrm{x}_{\mathrm{N}}$, because both are within a distance $\mathrm{q}$ from $\mathrm{x}_{\mathrm{N}}, 1 \leq \mathrm{N}-\mathrm{q} \leq \mathrm{i}, \mathrm{k} \leq \mathrm{N}-1$. Their respective compensation is the same, because each is set to the certainty equivalent of a gamble between $\ell$ and $s^{*}\left(\mathrm{x}_{\mathrm{N}}, \mathrm{x}_{\mathrm{N}}\right)$. Consequently, the TIC includes at least one flat region. ${ }^{23}$ This implies that the flat upper region cascades to lower flat regions for the outcomes that have $\mathrm{x}_{\mathrm{i}}, \mathrm{x}_{\mathrm{i}+1}, \ldots$, and $\mathrm{x}_{\mathrm{N}-\mathrm{q}-1}$ as target reports, and so on, if (TC) is binding for these lower outcomes as well. Part (c) establishes that truthful disclosure to the auditor, $D_{\mathrm{m}}^{*}(\mathrm{x})=\mathrm{x}$, is the agent's best response to the contract.

Figure 3 illustrates Proposition 2, Part (b), by showing the relationship between TIC payments and outcomes, where $s^{*}\left(\mathrm{X}_{\mathrm{i}}, \mathrm{X}_{\mathrm{k}}\right)$ is denoted by $s_{\mathrm{ik}}{ }^{24}$

Insert Figure 3 about here.

Note that contracts with flat regions are common when the principal designs truthinducing contracts. In Gjesdal (1989), the contract is a piecewise schedule; its increasing range lies on the $45^{\circ}$ line (the $\mathrm{x}$-axis is the report, and the $\mathrm{y}$-axis is the payment). ${ }^{25}$ The agent

\footnotetext{
${ }^{23}$ The general expression for all high outcomes that share the same target report is $\mathrm{U}\left(s\left(\mathrm{x}_{\mathrm{i}}, \mathrm{x}_{\mathrm{i}}\right)\right) \geq \pi \mathrm{U}(\ell)+(1-\pi) \mathrm{U}\left(s\left(\mathrm{x}_{\mathrm{N}}, \mathrm{x}_{\mathrm{N}}\right)\right), \quad \mathrm{N}-\mathrm{q} \leq \mathrm{i} \leq \mathrm{N}-1$.

${ }^{24}$ Figure 3 is a projection of the three-dimensional contract (payment $\mathrm{s}$ a function of the two signals) onto the two-dimensional plane of payment and the private report of the agent to the principal.
} 
reveals the truth because he either obtains the whole outcome or receives a fixed payment that is independent of what he reports. In our study, when the agent does not have LL, the contract is a strictly increasing schedule because the principal can use the audited report to discipline the agent. The combination of unobservability and LL creates the flat regions.

\subsection{The Comparison between TIC and RMC}

In this section we compare TIC and RMC. Since the contractible information in the RMC model (i.e., the auditor's report) is a subset of the contractible information in the TIC model, it follows immediately that the principal is never worse off with the TIC performance measures unless the contract space is more constrained in the latter than in the former. We show below that LL (along with two other conditions) determines whether a TIC is more constrained. If LL is too low to affect the contract (i.e., none of the (LC) and (TC) constraints is binding), a TIC is less costly than an RMC, because it is equivalent to a contract that is based on the actual outcome, $\mathrm{x}$, rather than on a noisy measure of the outcome, $r$. If LL affects the design of a TIC, eliciting the truth may be too costly. This situation results from the different roles of LL in the two types of contracts. In an RMC, LL guarantees a minimum payment to the agent. Without it, the principal prefers to pay the agent less. The cost of an RMC increases in LL because increasing LL will increase the risk premium that must be paid due to the incentive risk used to motivate the agent's actions. In a TIC, the minimum payment, $\ell$, acts as a lower-bound constraint on the penalty that can be

\footnotetext{
${ }^{25}$ The principal-agent game with an unobservable outcome and a perfect, costly monitor employed stochastically has been studied by Townsend (1979); Baiman and Demski (1980); Evans (1980); Gale and Hellwig (1985); Baiman, Evans, and Noel (1987); Border and Sobel (1988); Gjesdal (1989); and others. In Evans (1980), the monitor accurately detects both outcome and effort. Baiman and Demski (1980b) analyze a game in which the outcome is observable, but its decomposition into quantity and price variance is not. The principal must decide whether to monitor the agent ex post, costlessly, by acquiring information on these variances. They show that he prefers committing to the range of outcomes to trigger the variance analysis, rather than making the decision after the outcome is realized. Baiman, Evans, and Noel (1987) consider a tripartite game in which an auditor is a strategic player who is an intermediary between the principal and the agent.
} 
imposed. In equilibrium, the penalty is never imposed, but the threat of the penalty is crucial in the TIC contract. ${ }^{26}$ The cost of a TIC increases in $\ell$ because a higher LL level more tightly constrains the penalty that can be imposed.

Let the TIC be a step function. Index the steps in TIC by $\mathrm{t}, \mathrm{t}=1,2, .$. , such that $\mathrm{t}=1$ represents the highest step in the sense of being associated with the highest payment, $t=2$ is the step associated with the second highest payment, and so on, in descending order. Define by $\mathrm{t}(s(.,)$.$) the step associated with payment s(.,$.$) . Denote \mathrm{t}\left(s\left(\mathrm{x}_{\mathrm{i}}, \mathrm{x}_{\mathrm{i}}\right)\right)$ by $\mathrm{t}_{\mathrm{i}}$. If LL is so high that $\mathrm{N}-1$ (TC) constraints are binding, then each payment is a linear combination of $\ell$ and $s^{*}\left(\mathrm{x}_{\mathrm{N}}, \mathrm{X}_{\mathrm{N}}\right)$, the relative weight depends on $\mathrm{t}_{\mathrm{i}}, \mathrm{U}\left(s^{*}\left(\mathrm{x}_{\mathrm{i}}, \mathrm{X}_{\mathrm{i}}\right)\right)=\mathrm{U}(\ell)+$ $(1-\pi)^{\mathrm{t}_{\mathrm{i}}}\left[\mathrm{U}\left(s^{*}\left(\mathrm{x}_{\mathrm{N}}, \mathrm{x}_{\mathrm{N}}\right)\right)-\mathrm{U}(\ell)\right]$

We focus now on the equilibrium contracts when LL is high. We compare the TIC as just characterized with the RMC, which is a one-step schedule in which only the maximum payment, $c_{\mathrm{N}}$, exceeds the agent's LL level, $c^{*}\left(\mathrm{x}_{\mathrm{N}}\right)>\ell=c^{*}\left(\mathrm{x}_{\mathrm{i}}\right), \mathrm{i}=1,2, \ldots, \mathrm{N}-1$ (because N-1 $\left(\mathrm{LC}_{\mathrm{i}}\right)$ constraints are binding). We refer to these contracts wherein N-1 constraints are binding $\left(\left(\right.\right.$ whether $\left(\mathrm{LC}_{\mathrm{i}}\right)$ or $\left.\left(\mathrm{TC}_{\mathrm{ij}}\right)\right)$ as full LL- contracts.

In general, we can divide the payments into three categories:

1. If $\mathrm{i} \leq \mathrm{N}-\mathrm{q}-1, \mathrm{RMC}$ pays the agent $\ell$ whereas TIC pays more (see Proposition 2 ).

2. When $\mathrm{i}$ is higher, $\mathrm{N}-\mathrm{q} \leq \mathrm{i} \leq \mathrm{N}-1$, under both contracts the agent receives the expected utility of a gamble between the truth-telling payoff and earning the highest possible payment designated for $\mathrm{x}_{\mathrm{N}}$. Hence, the comparison of cost is determined by the largest possible payment under each contract, $c^{*}\left(\mathrm{x}_{\mathrm{N}}\right)$ and $s^{*}\left(\mathrm{x}_{\mathrm{N}}, \mathrm{x}_{\mathrm{N}}\right)$ and

\footnotetext{
${ }^{26}$ Our study thus differs from Gao (2006) whose manager can manage earnings and pay a penalty in equilibrium. The main difference between that study and ours is that in Gao's study the penalty is a parameter of the model. In our study, it is designed by the principal endogenously under the condition that it does not fall below the LL level. [Note that in our setting, discovery of the truth by the auditor does not trigger a penalty by the principal because the negotiations between the auditor and the manager are confidential].
} 
the agent's risk premium, since TIC replaces the gamble with its certainty equivalent.

3. The last category is the largest possible payoff, $\mathrm{i}=\mathrm{N}$, which again involves the comparison of $c^{*}\left(\mathrm{x}_{\mathrm{N}}\right)$ to $s^{*}\left(\mathrm{x}_{\mathrm{N}}, \mathrm{x}_{\mathrm{N}}\right)$.

\section{Proposition 3:}

Let the TIC and RMC be full LL contracts and let $\ell$ be sufficiently high such that (PC) is not binding. Then:

(a) There is a critical value of $\mathrm{q}$, denoted by $\hat{\mathrm{q}}, 1 \leq \hat{\mathrm{q}} \leq \mathrm{N}-2$, such that for all $\mathrm{q}$ 's, $\hat{\mathrm{q}} \leq \mathrm{q} \leq \mathrm{N}$ 2,

(i) the maximum payment under the TIC is larger than the maximum payment under the RMC, $s^{*}\left(\mathrm{x}_{\mathrm{N}}, \mathrm{x}_{\mathrm{N}}\right)>c^{*}\left(\mathrm{x}_{\mathrm{N}}\right)$.

(ii) the agent's payoff under the TIC is larger than his payoff under the RMC for each outcome; i.e., $\forall \mathrm{i}, \mathrm{U}\left(s^{*}\left(\mathrm{x}_{\mathrm{i}}, \mathrm{x}_{\mathrm{i}}\right)\right)>\mathrm{EU}\left(C^{*}(\mathrm{r}) \mid \mathrm{x}_{\mathrm{i}}\right)$.

(iii) the TIC costs more than the RMC if the agent is not too risk-averse, so that $\pi \ell+(1-\pi) c^{*}\left(\mathrm{x}_{\mathrm{N}}\right)<\mathrm{U}^{-1}\left(\pi \mathrm{U}(\ell)+(1-\pi) \mathrm{U}\left(s^{*}\left(\mathrm{x}_{\mathrm{N}}, \mathrm{x}_{\mathrm{N}}\right)\right)\right)$, and the principal demands report management.

(b) Let $\mathrm{q}=\mathrm{N}-1$. Then, $s^{*}\left(\mathrm{x}_{\mathrm{N}}, \mathrm{x}_{\mathrm{N}}\right)=c^{*}\left(\mathrm{x}_{\mathrm{N}}\right)$, and the TIC replaces the RMC's gambles by their certainty equivalents. The agent's utility is the same pointwise under both contracts. The TIC costs less than the RMC, and the principal demands the truth.

Proposition 3 shows that a TIC might be more costly when the LL level is high, depending on the reporting flexibility, q, and the risk-aversion of the agent. Part a(i) formulates conditions on $\mathrm{q}$ that guarantee that $s^{*}\left(\mathrm{x}_{\mathrm{N}}, \mathrm{X}_{\mathrm{N}}\right)>c^{*}\left(\mathrm{x}_{\mathrm{N}}\right)$. To understand the importance of the reporting flexibility, consider Figure 4. 
Insert Figure 4 about here.

The expected payment to the agent conditional on realized outcome are presented for $\mathrm{q}=3$ and $\mathrm{q}=13$ in an $\mathrm{N}=14$ example. ${ }^{27}$ The three categories of payments are evident for $\mathrm{q}=3$. Any reported outcome lower than $\mathrm{x}_{\mathrm{x}} \mathrm{x}_{11}$ awards the agent the LL level of 30 . But when outcome is $\mathrm{x}=\mathrm{x}_{11}, \mathrm{x}_{12}, \mathrm{x}_{13}$, the agent's expected payment is higher than the LL level because he may successfully inflate the reported outcome (to $\mathrm{x}=\mathrm{x}_{14}$ ). Finally, if $\mathrm{x}=\mathrm{x}_{14}$, he reports $\mathrm{x}=\mathrm{x}_{14}$ and receives the maximum payment. By contrast, when $\mathrm{q}=13$, the first category disappears and the second category expands.

As this figure illustrates, when LL is high, the riskiness of the RMC, as quantified by the agent's risk premium, is attributable to two features of the contract. One is the fact that the compensation for the highest reported outcome is the maximum payment under the contract. The second is the fact that the degree of reporting flexibility determines the range of reported outcomes for which the agent faces a lottery between the LL level and the maximum payment. As flexibility increases, this range of reported outcomes increases as well. Hence, the risk the contract imposes on the agent is higher when the degree of flexibility is higher. This higher riskiness, in turn, induces the agent more effectively to exert effort, thus allowing the principal to decrease the maximum payment. The relationship between $\mathrm{q}$, which is positively related to the risk the agent faces by accepting lotteries, and the maximum payment in the RMC contract, determines the overall riskiness of the contract. Figure 5 depicts the maximum payment and the risk premium of the agent for $\mathrm{N}=14$ and $\mathrm{q}$ is varied from 1 to 13

${ }^{27}$ Figure 4 is based on $\mathrm{N}=14, \operatorname{Pr}\left(\mathrm{x}_{\mathrm{i}} \mid a_{\mathrm{g}}\right)=0.05+0.1 *(\mathrm{i}-1)$ for $\mathrm{i}<14$, and $\operatorname{Pr}\left(\mathrm{x}_{14} \mid a_{\mathrm{g}}\right)=0.155 ; \operatorname{Pr}\left(\mathrm{x}_{\mathrm{i}} \mid a_{\mathrm{p}}\right)=$ $\operatorname{Pr}\left(\mathrm{x}_{14-\mathrm{i}} \mid a_{\mathrm{g}}\right) ; \mathrm{V}\left(a_{\mathrm{g}}\right)=70, \ell=30$. For presentation purposes, only the maximum payments $(373.13$ for $\mathrm{q}=3$ and 613.3 for $\mathrm{q}=13$ ) are divided by two. 
(the same parameters as in Figure 4 where the agent's utility function has a constant relative risk-aversion coefficient, $\left.\mathrm{U}(\mathrm{z})=\mathrm{z}^{1 / 2}\right)$.

Insert Figure 5 about here.

Part a(iii) shows that the lower payoff under RMC yields a lower contract cost if the agent is not too risk averse. The agent's risk-aversion determines the savings that accrue to the principal under a TIC by paying certainty equivalent amounts in lieu of the lotteries that the agent faces in the RMC program for the same class of payments.

Part (b) addresses the case when $\mathrm{q}=\mathrm{N}-1$. In this case, the agent's payoff is the same under both contracts, because even when outcome is as low as $\mathrm{x}_{1}$, RMC pays the agent a lottery. TIC dominates the RMC by replacing the RMC's lotteries with their certainty equivalents. In this case, the principal demands the truth for all LL levels.

\section{Proposition 4:}

Let:

(i) q be sufficiently large, $\hat{\mathrm{q}} \leq \mathrm{q} \leq \mathrm{N}-2$, and

(ii) the agent is not too risk-averse, as defined in Proposition 3, part (c).

Then, there exists a critical level of LL, $\ell$ ', such that for all lower (higher) LL levels a TIC is less (more) costly than an RMC. When the LL level is higher (lower) than $\ell$, the principal demands earnings management (the truth).

Proposition 4 is a direct result of Proposition 3, given that the contracts' cost increases in $\ell$ monotonously. Beyond a certain level of $\ell$, RMCs outperform TICs.

The earnings management literature quite often assumes that the truth is prohibitively costly in order to justify the inability to invoke the Revelation Principle. This assumption is 
introduced without motivation or explanation. In Propositions 3 and 4, we formulate three conditions that make truth-telling more costly than earnings management.

1) Limited liability.

2) Reporting flexibility.

3) The risk-aversion of the agent.

LL: When the LL level is high, so that RMC pays the agent $\ell$ for reporting the first $\mathrm{N}-1$ outcomes, the agent is reimbursed $\ell$ for sure for those outcomes with a target report that also pays $\ell$ (see Proposition 1). In contrast, in a TIC, each payment exceeds $\ell$ (Lemma 1). The algebra shows that when reporting flexibility is high and risk-aversion is low, this difference in payments to low reported outcomes make the RMC contract cheaper than TIC. Hence, the principal demands earnings management.

Reporting flexibility: If reporting flexibility, $\mathrm{q}$, is neither too low $(\mathrm{q}<\hat{\mathrm{q}})$ nor too high (the maximum, $\mathrm{q}=\mathrm{N}-1$ ), the agent's payoff under $\mathrm{RMC}$ is lower than under a TIC, because of the effect of $\mathrm{q}$ on the riskiness of the RMC, as discussed above.

Risk-aversion: The agent's risk-aversion determines the savings that accrue to the principal under a TIC by paying certainty equivalent amounts. If these savings are small, an RMC is relatively less costly.

Throughout the analysis, we have compared the types of contracts at a given LL level. Note that if the LL level changes in tandem with the reservation utility level, then the classification of the LL level as low (with little effect on the shape of the contract) or high becomes an empirical issue. In any case, our analysis highlights the trade-offs involved in choosing a TIC or an RMC. The former has the advantage of extracting a risk premium from the risk-averse agent, while the latter has the advantage of actually paying the agent his LL level, which decidedly reduces the cost of the first N-q-1 payments. 
We conclude the paper with the following examples, depicted in Figure 6, based on the following parameters: $\mathrm{N}=5, \mathrm{q}=1,2,3,4, \pi=0.80, \mathrm{U}_{0}=\mathrm{V}\left(a_{\mathrm{g}}\right)=70, \mathrm{~V}\left(a_{\mathrm{p}}\right)=0$. The probabilities of outcomes are: $\operatorname{Pr}\left(\mathrm{x}=\mathrm{x}_{1} \mid a_{\mathrm{g}}\right)=\operatorname{Pr}\left(\mathrm{x}=\mathrm{x}_{5} \mid a_{\mathrm{p}}\right)=0.06 ; \operatorname{Pr}\left(\mathrm{x}=\mathrm{x}_{2} \mid a_{\mathrm{g}}\right)=\operatorname{Pr}\left(\mathrm{x}=\mathrm{x}_{4} \mid a_{\mathrm{p}}\right)=0.12$; $\operatorname{Pr}\left(\mathrm{x}=\mathrm{x}_{3} \mid a_{\mathrm{g}}\right)=\operatorname{Pr}\left(\mathrm{x}=\mathrm{x}_{3} \mid a_{\mathrm{p}}\right)=0.22 ; \operatorname{Pr}\left(\mathrm{x}=\mathrm{x}_{4} \mid a_{\mathrm{g}}\right)=\operatorname{Pr}\left(\mathrm{x}=\mathrm{x}_{2} \mid a_{\mathrm{p}}\right)=0.24, \operatorname{Pr}\left(\mathrm{x}=\mathrm{x}_{5} \mid a_{\mathrm{g}}\right)=$ $\operatorname{Pr}\left(\mathrm{x}=\mathrm{x}_{1} \mid a_{\mathrm{p}}\right)=0.36$. We vary the LL levels. The cohorts of four columns correspond to $\mathrm{q}=4$, $\mathrm{q}=3, \mathrm{q}=2, \mathrm{q}=1$, respectively. The figure shows that $\hat{\mathrm{q}}=1$, so that the savings under an RMC (as compared to a TIC) are negative only when $\mathrm{q}=4$, and that for some LL levels, the savings increase in $\mathrm{q}$ for $\mathrm{q}=1,2,3$.

Insert Figure 6 about here.

\section{Conclusions}

We began with the following question: If earnings management is harmful to shareholders, why don't they design contracts that induce managers to reveal the truth? Our answer is that management's limited liability and the prevailing reporting flexibility may combine to render the cost of the truth higher than the benefit from learning the truth.

We show that when the agent's limited liability is sufficiently high, the principal might prefer a contract that induces report management (RMC) because limited liability reduces the effectiveness of the "sticks" in the compensation schedule to such an extent that the "carrots" that are required to induce effort and truth-telling become too expensive. Our study thus fills a lacuna in the Revelation Principle literature, which recognizes that the shape of the contract might induce earnings management (as in Healy [1985]) while ignoring the fact that because a contract is endogenously determined, an explanation of why it is a priori so designed is warranted. 


\section{References}

Arya, Anil, Jonathan C. Glover, and Shyam Sunder. (1998). "Earnings Management and the Revelation Principle." Review of Accounting Studies 3, 7-34.

Arya, Anil Jonathan C. Glover, and Shyam Sunder. (2003). "Are Unmanaged Earnings Always Better for Shareholders?" Accounting Horizons 17, 111-116.

Basu, Kaushik, Clive Bell, and Pinaki Bose. (2000). "Interlinkage, Limited Liability and Strategic Interaction." Journal of Economic Behavior and Organization 42, 445-462.

Christensen, Peter Ove and Jerald A. Feltham. (2005). Economics of Information, Volume II: Performance Evaluation. Springer-Verlag New York, LLC

Demougin, Dominiqe and Claude Fluet. (1998). "Mechanism Sufficient Statistic in the RiskNeutral Agency Problem." Journal of Institutional and Theoretical Economics 154, 622-639.

Demougin Dominique, and Claude Fluet (2001). "Monitoring versus Incentives". European Economic Review 45, 1741-1764.

Demski, Joel, S., Hans Frimor, and David E.M. Sappington. (2004). "Efficient Manipulation in a Repeated Setting". Journal of Accounting Research 42, 31-45.

Demski, Joel, S., David E.M. Sappington, and Pablo T. Spiller. (1988). "Incentive Schemes with Multiple Agents and Bankruptcy Constraints." Journal of Economic Theory 44, 156-167.

Dye, Ronald A. (1988). "Earnings Management in an Overlapping Generations Model." Journal of Accounting Research 26, 195-235.

Evans, John H., and Sri S. Sridhar. (1996). "Multiple Control Systems, Accrual Accounting, and Earnings Management." Journal of Accounting Research 34, 45-65.

Feltham, Gerald A., and Christian Hofmann. (2005). "Limited Commitment in Multi-agent Contracting." Sauder School of Business Working Paper No. \# Available at SSRN:

http://ssrn.com/abstract=716504

Feltham, G.A., and Jim Xie (1994) "Performance Measure Congruity and Diversity in MultiTask Principal/Agent Relations.” Accounting Review 69, 429-453.

Fields, Thomas D, Thomas Z. Lys, and Linda Vincent. (2001). "Empirical Research on Accounting Choice." Journal of Accounting and Economics. 31, 255-307.

Gao, Yanmin, (2006). "Is More Monitoring Better?" AAAA 2006 Financial Accounting and Reporting Section (FARS) Meeting Paper Available at SSRN:

http://ssrn.com/abstract $=815025$

Gjesdal, Forystein. (1989). "Piecewise linear incentives schemes". In Information and Incentives in Organizations edited by Seppo Honkapohja. Basil Blackwell, UK, Oxford and Cambridge. 
Harris, Milton, and Arthur Raviv. 1979. Optimal incentive contracts with imperfect information. Journal of Economic Theory 20, 231-259.

Healy, Paul M. (1985). "The Effect of Bonus Schemes on Accounting Decisions". Journal of Accounting and Economics 7, 85-107.

Healy, Paul M., and Krishna G. Palepu. (2001). "A Review of the Empirical Disclosure Literature". Journal of Accounting \& Economics 31, 405-440.

Healy, Paul M., and James M. Wahlen. (1999). "A Review of the Earnings Management Literature and its Implications for standard setting." Accounting Horizons 13, 365-383.

Holmstrom, Bengt. 1979. "Moral Hazard and Observability." Bell Journal of Economics 10, 7491.

Innes, Robert D. (1990). "Limited Liability and Incentive Contracting with Ex-ante Action Choices." Journal of Economic Theory 52, 45-67.

Kim, Son Ku. (1997). "Limited Liability and Bonus Contracts." Journal of Economics and Management Strategy 6, 899-913.

Kofman, Fred, and Jacques Lawarree. (1993). "Collusion in Hierarchical Agency." Econometrica 61, 629-656.

Kwon, Young K., Paul D. Newman, and Yoon, S. Suh. (2001). "The Demand for Accounting Conservatism for Management Control." Review of Accounting Studies 6, 29-52.

Laux, Christian. (2001). "Limited Liability and Incentive Contracting with Multiple Projects." Rand Journal of Economics 32, 514-526.

Matthews Steven A. (2001). "Renegotiating Moral-Hazard Contracts under Limited Liability and Monotonicity." Journal of Economic Theory 97, 1-29.

Myerson, Roger. (1979). Incentive Compatibility and the Bargaining Problem.” Econometrica 47, 61-73.

Park, Eun Soo. (1995). "Incentives Contracting under Limited Liability." Journal of Economics and Management Strategy 4: 477-490.

Rogerson, William P. (1985). "The first-Order Approach to Principal-Agent Problems." Econometrica 53, 1357-1368.

Ronen. Joshua, and Simcha Sadan. (1981). Smoothing Income Numbers: Objectives, Means, and Implications. Addison-Wesley Publishing Company.

Ronen, Joshua, Joseph Tzur, and Varda (Lewinstein) Yaari. (2006). “The Effect of Directors' Equity Incentives on Earnings Management." Journal of Accounting and Public Policy. Forthcoming. 
Ronen Joshua, and Varda (Lewinstein) Yaari. (2002). "Incentives for Voluntary Disclosure." Journal of Financial Markets 5, 349-390.

Ronen, Tavy, and Varda (Lewinstein) Yaari. 2002. "On the Tension between Full Revelation and Earnings Management: A Reconsideration of the Revelation Principle." Journal of Accounting, Auditing and Finance 17, 273-294.

Sappington, David E.M. (1983). "Limited Liability Contracts between Principal and Agent." Journal of economic Theory 29, 1-21.

Schwartz, Rachel (1997). "Legal Regimes, Audit Quality and Investment." The Accounting Review 72: 385-406.

Sherstyuk Katerina. (2003). "On Competitive Equilibria with Common Complementarities." Mathematical Social Science 46, 55-62. 


\section{APPENDIX}

\section{Proof of Proposition 1:}

We start the proof with the unlimited-liability contract. First we prove that when $q=1$ the contract is a strictly increasing function for any disclosure strategy. The agent's best response then is to inflate the disclosure, $D_{\mathrm{m}}\left(\mathrm{x}_{\mathrm{i}}\right)=\mathrm{x}_{\mathrm{i}+1}, \mathrm{i}<\mathrm{N}$. We next establish the purestrategy equilibrium when $\mathrm{q}=2$ and the (MLC) obtains. We conclude the characterization of the unlimited-liability contract by establishing that this equilibrium is unique.

As a preliminary, denote the argument that multiplies $\mu^{C}$ as $\mathrm{F}_{a}(\mathrm{x})$. As seen below, the proof is largely an exercise in comparing $\mathrm{F}_{a}$ for adjacent payments.

Lemma A1: When $q=1$, the equilibrium contract is a strictly increasing function of the report (for any disclosure strategy, $D_{\mathrm{m}}$ ).

Proof: We first assume that (IC. $D_{\mathrm{m}}$ ) is not binding, and then we prove that indeed it is not.

Suppose by contradiction that there is some outcome, $\mathrm{k}$, such that $c^{*}\left(\mathrm{x}_{\mathrm{k}}\right)>c^{*}\left(\mathrm{x}_{\mathrm{k}+1}\right)$,

$1 \leq \mathrm{k} \leq \mathrm{N}-1$. Since $\mathrm{x}_{\mathrm{k}+1}$ is no longer a target report for $\mathrm{x}_{\mathrm{k}}, \mathrm{F}_{a}\left(\mathrm{x}_{\mathrm{k}+1}\right)$ equals $1-\frac{\operatorname{Prob}\left[\mathrm{x}_{\mathrm{k}+1} \mid a_{\mathrm{p}}\right]}{\operatorname{Prob}\left[\mathrm{x}_{\mathrm{k}+1} \mid a_{\mathrm{g}}\right]}$

if it is not a target report for $\mathrm{x}_{\mathrm{k}+2}$ or $1-\frac{\operatorname{Prob}\left[\mathrm{x}_{\mathrm{k}+1} \mid a_{\mathrm{p}}\right]+(1-\pi) \operatorname{Prob}\left[\mathrm{x}_{\mathrm{k}+2} \mid a_{\mathrm{p}}\right]}{\operatorname{Prob}\left[\mathrm{x}_{\mathrm{k}+1} \mid a_{\mathrm{g}}\right]+(1-\pi) \operatorname{Prob}\left[\mathrm{x}_{\mathrm{k}+2} \mid a_{\mathrm{p}}\right]}$ if it is.

Similarly, for $c_{\mathrm{k}}^{*}, \mathrm{~F}_{a}\left(\mathrm{x}_{\mathrm{k}}\right)$ is $1-\frac{\operatorname{Prob}\left[\mathrm{x}_{\mathrm{k}} \mid a_{\mathrm{p}}\right]}{\operatorname{Prob}\left[\mathrm{x}_{\mathrm{k}} \mid a_{\mathrm{g}}\right]}$ if $\mathrm{x}_{\mathrm{k}}$ is not a target report for $\mathrm{x}_{\mathrm{k}-2}$ and 
$1-\frac{\operatorname{Prob}\left[\mathrm{x}_{\mathrm{k}} \mid a_{\mathrm{p}}\right]+(1-\pi) \operatorname{Prob}\left[\mathrm{x}_{\mathrm{k}-1} \mid a_{\mathrm{p}}\right]}{\operatorname{Prob}\left[\mathrm{x}_{\mathrm{k}} \mid a_{\mathrm{g}}\right]+(1-\pi) \operatorname{Prob}\left[\mathrm{x}_{\mathrm{k}-1} \mid a_{\mathrm{p}}\right]}$ if it is. By the MLRC,

$1-\frac{\operatorname{Prob}\left[\mathrm{x}_{\mathrm{k}} \mid a_{\mathrm{p}}\right]+(1-\pi) \operatorname{Prob}\left[\mathrm{x}_{\mathrm{k}-1} \mid a_{\mathrm{p}}\right]}{\operatorname{Prob}\left[\mathrm{x}_{\mathrm{k}} \mid a_{\mathrm{g}}\right]+(1-\pi) \operatorname{Prob}\left[\mathrm{x}_{\mathrm{k}-1} \mid a_{\mathrm{p}}\right]}<1-\frac{\operatorname{Prob}\left[\mathrm{x}_{\mathrm{k}} \mid a_{\mathrm{p}}\right]}{\operatorname{Prob}\left[\mathrm{x}_{\mathrm{k}} \mid a_{\mathrm{g}}\right]}<1-\frac{\operatorname{Prob}\left[\mathrm{x}_{\mathrm{k}+1} \mid a_{\mathrm{p}}\right]}{\operatorname{Prob}\left[\mathrm{x}_{\mathrm{k}+1} \mid a_{\mathrm{g}}\right]}<$

$1-\frac{\operatorname{Prob}\left[\mathrm{x}_{\mathrm{k}+1} \mid a_{\mathrm{p}}\right]+(1-\pi) \operatorname{Prob}\left[\mathrm{x}_{\mathrm{k}+2} \mid a_{\mathrm{p}}\right]}{\operatorname{Prob}\left[\mathrm{x}_{\mathrm{k}+1} \mid a_{\mathrm{g}}\right]+(1-\pi) \operatorname{Prob}\left[\mathrm{x}_{\mathrm{k}+2} \mid a_{\mathrm{p}}\right]}$, which yields the required contradiction.

It is easy to verify that the solution of an RMC with nonbinding (IC. $D_{\mathrm{m}}$ ) satisfies the principal's program. Q.E.D.

The case where $\mathrm{q}>1$ is relevant only if $\mathrm{N} \geq 3$. We still solve for the unlimited-liability RMC. We show that the principal's best response to a disclosure strategy that maximally inflates the report is to design a non-decreasing compensation contract, and that this disclosure strategy is the agent's best response to a strictly increasing schedule.

Let the agent manage the report by inflating the disclosure; i.e., $D_{\mathrm{m}}\left(\mathrm{x}_{\mathrm{i}}\right)=\mathrm{x}_{\min \{\mathrm{i}+\mathrm{q}, \mathrm{N}\}}$. Then,

$$
\operatorname{Prob}\left[\mathrm{r}=\mathrm{x}_{\mathrm{i}} \mid D_{\mathrm{m}}\right]= \begin{cases}\pi \operatorname{Prob}\left[\mathrm{x}_{\mathrm{i}} \mid a_{\mathrm{g}}\right] & \text { for } 1 \leq \mathrm{i} \leq \mathrm{q} \\ \pi \operatorname{Prob}\left[\mathrm{x}_{\mathrm{i}} \mid a_{\mathrm{g}}\right]+(1-\pi) \operatorname{Prob}\left[\mathrm{x}_{\mathrm{i}-\mathrm{q}} \mid a_{\mathrm{g}}\right] & \text { for } \mathrm{q}+1 \leq \mathrm{i} \leq \mathrm{N}-1 \\ \operatorname{Prob}\left[\mathrm{x}_{\mathrm{i}} \mid a_{\mathrm{g}}\right]+(1-\pi) \operatorname{Prob}\left[\mathrm{x}_{\mathrm{i}-\mathrm{q}} \mid a_{\mathrm{g}}\right] & \text { for } \mathrm{i}=\mathrm{N}\end{cases}
$$

When $1 \leq \mathrm{i} \leq \mathrm{q}$, the report must be the truth that was discovered by the auditor; when $\mathrm{q}+1 \leq \mathrm{i} \leq \mathrm{N}-1$, either the auditor discovered the truth, or the auditor did not discover an attempt to issue a target report for a lower outcome; and when $\mathrm{i}=\mathrm{N}$, either the report is the truth, because $r=x_{N}$ is the target report for $x_{N}$, or the auditor did not discover misrepresentation of a lower outcome. 
Substituting (A1) into the first-order conditions (FOC) of the principal's program, noting that $\left(\mathrm{IC} . D_{\mathrm{m}}\right)$ are not binding, yields

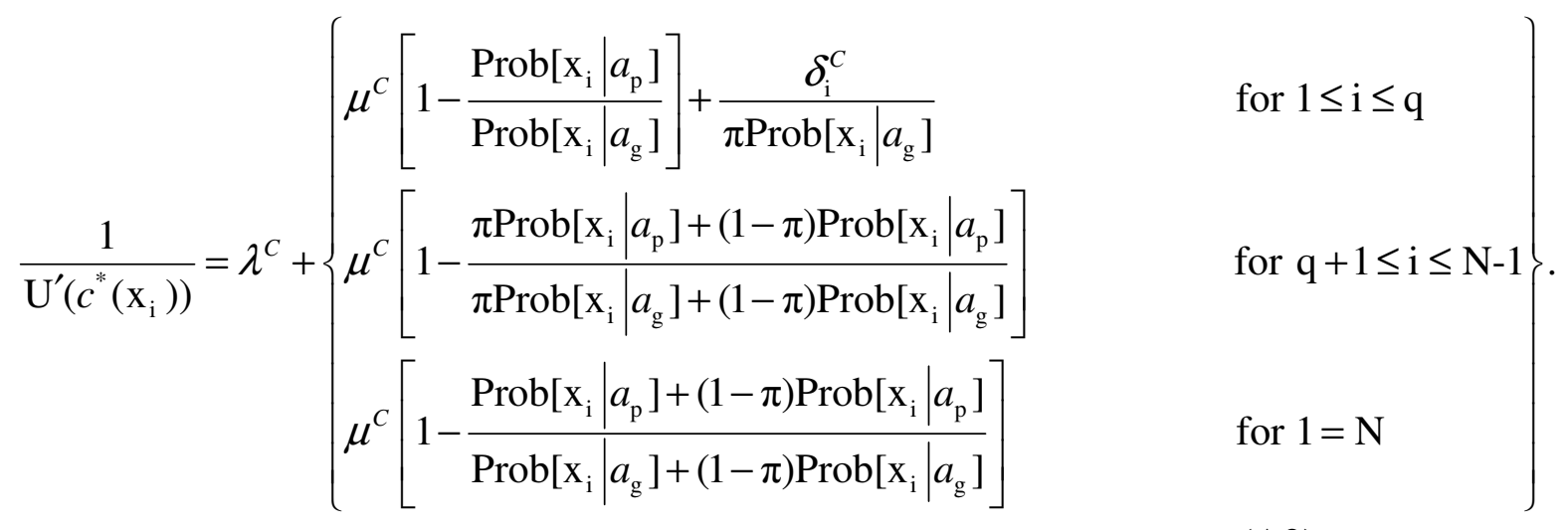

By the MLRC, the contract is a strictly increasing function for $\mathrm{i} \leq \mathrm{q}$. The comparison of two consecutive payments and $c^{*}\left(\mathrm{x}_{\mathrm{i}+1}\right)^{28}$ yields a strictly increasing schedule if

$$
\frac{\pi \operatorname{Prob}\left[\mathrm{x}_{\mathrm{i}+1} \mid a_{\mathrm{p}}\right]+(1-\pi) \operatorname{Prob}\left[\mathrm{x}_{\mathrm{i}+1-\mathrm{q}} \mid a_{\mathrm{p}}\right]}{\pi \operatorname{Prob}\left[\mathrm{x}_{\mathrm{i}+1} \mid a_{\mathrm{g}}\right]+(1-\pi) \operatorname{Prob}\left[\mathrm{x}_{\mathrm{i}+1-\mathrm{q}} \mid a_{\mathrm{g}}\right]}<\frac{\pi \operatorname{Prob}\left[\mathrm{x}_{\mathrm{i}} \mid a_{\mathrm{p}}\right]+(1-\pi) \operatorname{Prob}\left[\mathrm{x}_{\mathrm{i}-\mathrm{q}} \mid a_{\mathrm{p}}\right]}{\pi \operatorname{Prob}\left[\mathrm{x}_{\mathrm{i}} \mid a_{\mathrm{g}}\right]+(1-\pi) \operatorname{Prob}\left[\mathrm{x}_{\mathrm{i}-\mathrm{q}} \mid a_{\mathrm{g}}\right]} .
$$

In order to analyze (A3), we use the following abbreviations:
$\underline{\mathrm{A}}$
$=\quad \operatorname{Prob}\left[\mathrm{x}_{\mathrm{i}} \mid a_{\mathrm{p}}\right]$
$\underline{\mathrm{E}} \quad=\operatorname{Prob}\left[\mathrm{x}_{\mathrm{i}-\mathrm{q}} \mid a_{\mathrm{p}}\right]$
B $\quad=\quad \operatorname{Prob}\left[\mathrm{x}_{\mathrm{i}} \mid a_{\mathrm{g}}\right]$
$\underline{\mathrm{F}} \quad=\operatorname{Prob}\left[\mathrm{x}_{\mathrm{i}-\mathrm{q}} \mid a_{\mathrm{g}}\right]$
$\underline{\mathrm{C}}$
$\operatorname{Prob}\left[\mathrm{x}_{\mathrm{i}+1} \mid a_{\mathrm{p}}\right]$
$\underline{\mathrm{G}} \quad=\quad \operatorname{Prob}\left[\mathrm{x}_{\mathrm{i}+1-\mathrm{q}} \mid a_{\mathrm{p}}\right]$
$\underline{\mathrm{D}}$
$\operatorname{Prob}\left[\mathrm{x}_{\mathrm{i}+1} \mid a_{\mathrm{g}}\right]$
$\underline{\mathrm{H}} \quad=\operatorname{Prob}\left[\mathrm{x}_{\mathrm{i}+1-\mathrm{q}} \mid a_{\mathrm{g}}\right]$

(A3) then is: $\frac{\pi \underline{\mathrm{A}}+(1-\pi) \underline{\mathrm{E}}}{\pi \underline{\mathrm{B}}+(1-\pi) \underline{\mathrm{F}}}>\frac{\pi \underline{\mathrm{C}}+(1-\pi) \overline{\mathrm{G}}}{\pi \underline{\mathrm{D}}+(1-\pi) \overline{\mathrm{H}}} . C$ is an increasing function of $\mathrm{r}$ only if $\pi^{2}(\underline{\mathrm{AD}}-\underline{\mathrm{CB}})+\pi(1-\pi)(\underline{\mathrm{AH}}-\underline{\mathrm{GB}}+\underline{\mathrm{ED}}-\underline{\mathrm{CF}})+(1-\pi)^{2}(\underline{\mathrm{EH}}-\underline{\mathrm{GF}})>0 .(\mathrm{A} 4)$

28 The proof for the comparison of $c\left(\mathrm{x}_{\mathrm{q}}\right)$ to $c\left(\mathrm{x}_{\mathrm{q}+1}\right)$ is similar to the proofs below. 
Because the first and third arguments are positive, (A4) is positive if the second argument is non-negative, which obtains when $\frac{\underline{F}}{\underline{H}} \geq \frac{\underline{B}}{\underline{D}} \cdot 29$ The proof of the unlimitedliability RMC is concluded upon establishing the uniqueness of this equilibrium. The proof is by induction on $\mathrm{q}$.

Step 1: The proof for $\mathrm{q}=1$ : See Lemma A1.

Step 2: The assumption: Suppose that this equilibrium is unique for some $\hat{\mathrm{q}}, \hat{\mathrm{q}}<\mathrm{N}-1$.

Step 3. The proof that the equilibrium is unique for $\mathrm{q}=\hat{\mathrm{q}}+1$.

Suppose that $\mathrm{q}=\mathrm{N}-1$. In this case, the agent attempts to manipulate every outcome's disclosure to the outcome that yields the global maximum, unless the truth coincides with the outcome that yields the maximum payment. If $c^{*}\left(\mathrm{x}_{\mathrm{N}}\right)$ is the globally maximum payment, then the contract is a strictly increasing function by the MLRC. Suppose, by contradiction, that the globally maximum payment is different, say $c^{*}\left(\mathrm{x}_{\mathrm{k}}\right)$. It is immediate to see that by the MLRC, the first-order condition for $c\left(\mathrm{x}_{\mathrm{N}}\right)$ yield a higher payment for $c\left(\mathrm{x}_{\mathrm{N}}\right)$ than for $c\left(\mathrm{x}_{\mathrm{k}}\right)$, since $1-\frac{\operatorname{Prob}\left[\mathrm{x}_{\mathrm{N}} \mid a_{\mathrm{p}}\right]}{\operatorname{Prob}\left[\mathrm{x}_{\mathrm{N}} \mid a_{\mathrm{g}}\right]}>1-\frac{\operatorname{Prob}\left[\mathrm{x}_{\mathrm{k}} \mid a_{\mathrm{p}}\right]+(1-\pi) \sum_{\mathrm{i}, 1 \leq i \leq N, \mathrm{i} \neq \mathrm{k}} \operatorname{Prob}\left[\mathrm{x}_{\mathrm{i}} \mid a_{\mathrm{p}}\right]}{\operatorname{Prob}\left[\mathrm{x}_{\mathrm{k}} \mid a_{\mathrm{g}}\right]+(1-\pi) \sum_{\mathrm{i}, 1 \leq i \leq N, \mathrm{i} \neq \mathrm{k}} \operatorname{Prob}\left[\mathrm{x}_{\mathrm{i}} \mid a_{\mathrm{p}}\right]}=1-\frac{\pi \operatorname{Prob}\left[\mathrm{x}_{\mathrm{k}} \mid a_{\mathrm{p}}\right]}{\pi \operatorname{Prob}\left[\mathrm{x}_{\mathrm{k}} \mid a_{\mathrm{g}}\right]}$. ${ }^{29}(\underline{\mathrm{AH}}-\underline{\mathrm{GB}}+\underline{\mathrm{ED}}-\underline{\mathrm{CF}})=\left[-\underline{\mathrm{BH}}\left(\underline{\underline{\underline{\mathrm{G}}}}-\frac{\underline{\mathrm{A}}}{\underline{B}}\right)+\underline{\mathrm{FD}}\left(\left(\frac{\underline{\mathrm{E}}}{\underline{\mathrm{F}}}-\underline{\underline{\mathrm{C}}}\right)\right] \geq[\underline{\mathrm{DD}}-\underline{\mathrm{BH}}]\left(\frac{\underline{\mathrm{E}}}{\underline{\mathrm{F}}}-\underline{\underline{\mathrm{C}}}\right) \geq 0\right.$. The first inequality follows from the MLRC. The second inequality obtains when $\frac{\vec{F}}{\underline{H}} \geq \frac{\underline{B}}{\underline{D}}$. 
Next, consider $\hat{\mathrm{q}}+1=\mathrm{N}-2$. If the global maximum is lower than $\mathrm{x}_{\mathrm{N}}$ and higher than $\mathrm{x}_{1}$, all the reports are manipulated to this global payoff report and, as proved for the case where $\hat{\mathrm{q}}+1=\mathrm{N}-1$, the required contradiction obtains. If $c^{*}\left(\mathrm{x}_{\mathrm{N}}\right)$ is the globally maximum payment, we have to prove that $c^{*}\left(\mathrm{x}_{1}\right)<c^{*}\left(\mathrm{x}_{2}\right)$. Since neither $\mathrm{x}_{1}$ nor $\mathrm{x}_{2}$ is a target report, the comparison of $\mathrm{F}_{a}\left(\mathrm{x}_{1}\right)$ to $\mathrm{F}_{a}\left(\mathrm{x}_{2}\right)\left(\mathrm{F}_{a}\right.$ as defined above) yields the required contradiction by the MLRC. Next, if the globally maximum payment obtains for $\mathrm{r}=\mathrm{x}_{1}$, the MLRC ensures that the first-order conditions of $c\left(\mathrm{x}_{\mathrm{N}}\right)$ yield a higher payment than the first-order conditions of $c\left(\mathrm{x}_{1}\right)$, in a similar fashion to the case where $\hat{\mathrm{q}}+1=\mathrm{N}-1$, which thus yields the required contradiction.

Proceeding in this fashion until $\mathrm{q}=\hat{\mathrm{q}}+1$ concludes the proof.

\section{$\underline{\operatorname{Part}(b):}$}

This part is based on Part (a), which proves that the contract is a strictly increasing function if it is not affected by LL. If some $\left(\mathrm{LC}_{\mathrm{i}}\right)$ are binding, it is clear that when a given payment exceeds $\ell$, all higher reports yield payments that exceed $\ell$ even more, and when a given payment is determined by $\ell$, all lower reports pay $\ell$ as well. It is straightforward to verify that the agent's disclosure to the auditor is the best response to the piecewise contract. Q.E.D.

\section{Proof of Lemma 1:}

The proof is based on showing that if there were a single payment at the level of $\ell$, then the contract would elicit the truth only if the TIC were a flat wage at the level of $\ell$, which violates assumption A1(ii). Suppose, by contradiction, that there is at least one binding $\left(\mathrm{LC}_{\mathrm{i}}\right)$, i.e., $s\left(\mathrm{x}_{\mathrm{i}}, \mathrm{x}_{\mathrm{i}}\right)=$, which, by $\left(\mathrm{TC}_{\mathrm{ij}}\right)$, implies that 
$\forall \mathrm{j}, 1 \leq \mathrm{i}-\mathrm{q} \leq \mathrm{j} \leq \mathrm{i}+\mathrm{q} \leq \mathrm{N}, \quad \mathrm{U}\left(s\left(\mathrm{x}_{\mathrm{i}}, \mathrm{x}_{\mathrm{i}}\right)\right)=\mathrm{U}(\ell) \geq \pi \mathrm{U}(\ell)+(1-\pi) \mathrm{U}\left(s\left(\mathrm{x}_{\mathrm{j}}, \mathrm{x}_{\mathrm{j}}\right)\right)$.

Rearranging (A5) yields

$\forall \mathrm{j}, 1 \leq \mathrm{i}-\mathrm{q} \leq \mathrm{j} \leq \mathrm{i}+\mathrm{q} \leq \mathrm{N}, \quad \mathrm{U}(\ell) \geq \mathrm{U}\left(s\left(\mathrm{x}_{\mathrm{j}}, \mathrm{x}_{\mathrm{j}}\right)\right)$.

However, because $\ell$ is the lowest feasible payment,

$\forall \mathrm{j}, 1 \leq \mathrm{i}-\mathrm{q} \leq \mathrm{j} \leq \mathrm{i}+\mathrm{q} \leq \mathrm{N}, \quad \mathrm{U}(\ell) \leq \mathrm{U}\left(s\left(\mathrm{x}_{\mathrm{j}}, \mathrm{x}_{\mathrm{j}}\right)\right)$.

(A6) and (A7) hold only if both are a strict equality; i.e., $s\left(\mathrm{x}_{\mathrm{j}}, \mathrm{x}_{\mathrm{j}}\right)=s\left(\mathrm{x}_{\mathrm{i}}, \mathrm{x}_{\mathrm{i}}\right)=\ell$. A single payment of $\ell$ implies that all the payments within a distance of q must equal $\ell$ as well. Hence, by construction, it can be shown that all payments that are multiples of q distant are also equal to $\ell$, and so on until the contract becomes a flat wage. Q.E.D.

\section{Proof of Proposition 2:}

The proof is based on the following two lemmas, whose proofs are available upon request from the authors.

LEMMA A2: The contract is a non-decreasing function of the outcome.

\section{LEMMA A3:}

a) If $s\left(\mathrm{x}_{\mathrm{i}-1}, \mathrm{X}_{\mathrm{i}-1}\right)=s\left(\mathrm{x}_{\mathrm{i}}, \mathrm{X}_{\mathrm{i}}\right)$, then both $\left(\mathrm{TC}_{\mathrm{i}-1, \mathrm{i}-1+\mathrm{q}}\right)$ and $\left(\mathrm{TC}_{\mathrm{i}, \mathrm{i}+\mathrm{q}}\right)$ are binding.

b) $s\left(\mathrm{X}_{\mathrm{N}}, \mathrm{X}_{\mathrm{N}}\right)>s\left(\mathrm{X}_{\mathrm{N}-1}, \mathrm{X}_{\mathrm{N}-1}\right)$.

Part (a): Case 1: $\mathrm{q}=1$.

The proof is based on unraveling the contract from $s\left(\mathrm{x}_{\mathrm{N}}, \mathrm{X}_{\mathrm{N}}\right)$ to $s\left(\mathrm{x}_{1}, \mathrm{X}_{1}\right)$. By Lemma A3, Part $(\mathrm{b}), s\left(\mathrm{X}_{\mathrm{N}}, \mathrm{X}_{\mathrm{N}}\right)>s\left(\mathrm{X}_{\mathrm{N}-1}, \mathrm{X}_{\mathrm{N}-1}\right)$. We next prove that $s\left(\mathrm{x}_{\mathrm{N}-2}, \mathrm{X}_{\mathrm{N}-2}\right)>s\left(\mathrm{X}_{\mathrm{N}-1}, \mathrm{X}_{\mathrm{N}-1}\right)$. Suppose, by contradiction, that it is not, i.e., by Lemma A2, $s\left(\mathrm{X}_{\mathrm{N}-2}, \mathrm{X}_{\mathrm{N}-2}\right)=s\left(\mathrm{X}_{\mathrm{N}-1}, \mathrm{X}_{\mathrm{N}-1}\right)$. Then, by Lemma A3, Part (a), $\left(\mathrm{TC}_{\mathrm{N}-2, \mathrm{~N}-1}\right)$ and $\left(\mathrm{TC}_{\mathrm{N}-1, \mathrm{~N}}\right)$ are binding. 


$$
\begin{aligned}
& \mathrm{U}\left(s\left(\mathrm{x}_{\mathrm{N}-2}, \mathrm{X}_{\mathrm{N}-2}\right)\right)=\pi \mathrm{U}(\ell)+(1-\pi) \mathrm{U}\left(s\left(\mathrm{x}_{\mathrm{N}-1}, \mathrm{X}_{\mathrm{N}-1}\right)\right) . \\
& \mathrm{U}\left(s\left(\mathrm{x}_{\mathrm{N}-1}, \mathrm{x}_{\mathrm{N}-1}\right)\right)=\pi \mathrm{U}(\ell)+(1-\pi) \mathrm{U}\left(s\left(\mathrm{x}_{\mathrm{N}}, \mathrm{X}_{\mathrm{N}}\right)\right) .
\end{aligned}
$$

Subtracting (A9) from (A8) yields the required contradiction, because $s\left(\mathrm{x}_{\mathrm{N}}, \mathrm{x}_{\mathrm{N}}\right)>$ $s\left(\mathrm{X}_{\mathrm{N}-1}, \mathrm{X}_{\mathrm{N}-1}\right)$. Proceeding in this fashion to $s\left(\mathrm{x}_{1}, \mathrm{X}_{1}\right)$ completes the proof.

Case 2: $\mathrm{q}>1$, and at most one $\left(\mathrm{TC}_{\mathrm{iN}}\right)$ is binding.

By Lemma (A2) and Lemma (A3), Part (a), $s\left(\mathrm{x}_{\mathrm{j}-1}, \mathrm{X}_{\mathrm{j}-1}\right)=s\left(\mathrm{x}_{\mathrm{j}}, \mathrm{X}_{\mathrm{j}}\right)$ requires that two (TC) be binding. Having just one implies that $s\left(\mathrm{x}_{\mathrm{j}-1}, \mathrm{x}_{\mathrm{j}-1}\right)<s\left(\mathrm{x}_{\mathrm{j}}, \mathrm{X}_{\mathrm{j}}\right)$.

Part (c): The proof is immediate from the fact that deviation from truthful disclosure can be detected with some positive probability and penalized. Q.E.D.

\section{Proof of Proposition 3:}

When all $\left(\mathrm{LC}_{\mathrm{i}}\right)$ are binding for an RMC (with the exception of $\left(\mathrm{LC}_{\mathrm{Nj}}\right)$ ), the first $\mathrm{N}-1$ payments equal $\ell$, and $c^{*}\left(\mathrm{x}_{\mathrm{N}}\right)$ is determined by (IC). That is,

$$
\Delta \mathrm{P}_{\mathrm{N}} \mathrm{U}\left(c\left(\mathrm{x}_{\mathrm{N}}\right)\right)+\sum_{\mathrm{i}=\mathrm{N}-\mathrm{q}}^{\mathrm{N}-1} \Delta \mathrm{P}_{\mathrm{i}}\left[\pi \mathrm{U}(\ell)+(1-\pi) \mathrm{U}\left(c\left(x_{\mathrm{N}}\right)\right)\right]+\sum_{\mathrm{i}=1}^{\mathrm{N}-\mathrm{q}-1} \Delta \mathrm{P}_{\mathrm{i}} \mathrm{U}(\ell)=\mathrm{V}\left(a_{\mathrm{g}}\right)-\mathrm{V}\left(a_{\mathrm{p}}\right)
$$

where: $\Delta \mathrm{P}_{\mathrm{i}}=\operatorname{Prob}\left[\mathrm{x}_{\mathrm{i}} \mid a_{\mathrm{g}}\right]-\operatorname{Prob}\left[\mathrm{x}_{\mathrm{i}} \mid a_{\mathrm{p}}\right]$.

In a TIC, $s\left(\mathrm{x}_{\mathrm{N}}, \mathrm{x}_{\mathrm{N}}\right)$ is also solved from (IC), and the rest of the payments are found by $\left(\mathrm{TC}_{\mathrm{i}, \min \{\mathrm{i}+\mathrm{q}, \mathrm{N}\}}\right)$. Each payoff is a linear combination of $\ell$ and the maximum payment, $s^{*}\left(\mathrm{X}_{\mathrm{N}}, \mathrm{X}_{\mathrm{N}}\right)$; the weights depend on the distance of the step to which the payment pertains from $s^{*}\left(\mathrm{X}_{\mathrm{N}}, \mathrm{X}_{\mathrm{N}}\right), \mathrm{Q}_{\mathrm{i}}$. By (IC), 


$$
\begin{aligned}
\Delta \mathrm{P}_{\mathrm{N}} \mathrm{U}\left(s\left(\mathrm{x}_{\mathrm{N}}, \mathrm{x}_{\mathrm{N}}\right)\right)+\sum_{\mathrm{i}=\mathrm{N}-\mathrm{q}}^{\mathrm{N}-1} \Delta \mathrm{P}_{\mathrm{i}}\left[\pi \mathrm{U}(\ell)+(1-\pi) \mathrm{U}\left(s\left(\mathrm{x}_{\mathrm{N}}, \mathrm{x}_{\mathrm{N}}\right)\right)\right]+ \\
\quad \sum_{\mathrm{i}=1}^{\mathrm{N}-\mathrm{q}-1} \Delta \mathrm{P}_{\mathrm{i}} \mathrm{U}(\ell)+\left[\mathrm{U}\left(s\left(\mathrm{x}_{\mathrm{N}}, \mathrm{x}_{\mathrm{N}}\right)\right)-\mathrm{U}(\ell)\right] \Omega=\mathrm{V}\left(a_{\mathrm{g}}\right)-\mathrm{V}\left(a_{\mathrm{p}}\right),
\end{aligned}
$$

where $\Omega=\sum_{\mathrm{i}=1}^{\mathrm{N}-\mathrm{q}-1} \Delta \mathrm{P}_{\mathrm{i}}(1-\pi)^{\mathrm{t}_{\mathrm{i}}}$.

A comparison of the (IC)'s for TIC and for RMC shows that if $\Omega<0$,

$s^{*}\left(\mathrm{x}_{\mathrm{N}}, \mathrm{x}_{\mathrm{N}}\right)>c^{*}\left(\mathrm{x}_{\mathrm{N}}\right)$. Next, define the probability ratio as $\mathrm{g}(\mathrm{i})$; i.e., $\mathrm{g}(\mathrm{i})=\frac{\operatorname{Prob}\left(\mathrm{x}_{\mathrm{i}} \mid a_{\mathrm{g}}\right)}{\operatorname{Prob}\left(\mathrm{x}_{\mathrm{i}} \mid a_{\mathrm{p}}\right)}$,

where, by the MLRC, $g$ is a strictly increasing function of $i$.

$$
\Delta \mathrm{P}_{\mathrm{i}}=\operatorname{Prob}\left[\mathrm{x}_{\mathrm{i}} \mid a_{\mathrm{g}}\right]-\operatorname{Prob}\left[\mathrm{x}_{\mathrm{i}} \mid a_{\mathrm{p}}\right]=\operatorname{Prob}\left[\mathrm{x}_{\mathrm{i}} \mid a_{\mathrm{p}}\right][\mathrm{g}(\mathrm{i})-1] .
$$

Since $\sum_{\mathrm{i}=1}^{\mathrm{N}} \operatorname{Prob}\left[\mathrm{x}_{\mathrm{i}} \mid a_{\mathrm{g}}\right]-\operatorname{Prob}\left[\mathrm{x}_{\mathrm{i}} \mid a_{\mathrm{p}}\right]=0$, by the MLRC, $\mathrm{g}(\mathrm{i})<1$ for low outcomes and $\mathrm{g}(\mathrm{i})>1$ for high outcomes, so that when $\mathrm{q}$ is large, $\Delta \mathrm{P}_{\mathrm{i}}\left[\mathrm{U}\left(s_{\mathrm{NN}}\right)-\mathrm{U}(\ell)\right]<0$ pointwise, which implies that $\Omega<0$.

Completing the proof requires showing that $\hat{\mathrm{q}}$ is the minimum $\mathrm{q}$ for which $\Omega<0$ and that $\hat{\mathrm{q}}<\mathrm{N}-1$. At $\mathrm{q}=\mathrm{N}-2, \Omega \approx \Delta \mathrm{P}_{1}<0$, since $\mathrm{g}_{1}<1$. To prove that $\hat{\mathrm{q}}$ is the minimum $\mathrm{q}$, note that, by definition, the lower $\mathrm{q}$ is, the greater the number of arguments that enter $\Omega$ (because the summation is from $\mathrm{i}=1$ to $\mathrm{i}=\mathrm{N}-\mathrm{q}-1)$, and $(1-\pi)^{\mathrm{t}_{\mathrm{i}}}$ is an increasing function. Once $\Omega$ contains arguments with $g_{i}$ (weakly) exceeding one, each additional argument is positive; i.e., $\sum_{\mathrm{i}=1}^{\mathrm{N}-\hat{\mathrm{q}}^{-1}} \Delta \mathrm{P}_{\mathrm{i}}(1-\pi)^{\mathrm{t}_{\mathrm{i}}}-\sum_{\mathrm{i}=1}^{\mathrm{N}-(\hat{\mathrm{q}}-1)-1} \Delta \mathrm{P}_{\mathrm{i}}(1-\pi)^{\mathrm{t}_{\mathrm{i}}}=\Delta \mathrm{P}_{\mathrm{N}-\mathrm{q}^{*}}(1-\pi)^{\mathrm{t}_{\mathrm{N}-q}}>0$.

\section{$\underline{\text { Parts (aii-aiii-b): }}$}


The proof is straightforward from Part (a) and the discussion in the text. Part (b) is based on (IC.a), which is used to establish that $s^{*}\left(\mathrm{x}_{\mathrm{N}}, \mathrm{x}_{\mathrm{N}}\right)=c^{*}\left(\mathrm{x}_{\mathrm{N}}\right)$. Hence, although the two contracts yield the agent the same payoff, the RMC offers the agent a lottery between $\ell$ and the maximum payment when $x_{i}<x_{N}$, while the TIC offers the certainty equivalent of this lottery. Q.E.D.

\section{Proof of Proposition 4:}

Since a TIC dominates an RMC for low $\ell$ and, by Proposition 3, an RMC dominates a TIC for high $\ell$, the proof is complete upon establishing that the contracts' costs is a monotone increasing function of $\ell$, because then the contracts' costs intersect once, at the critical level $\ell^{\prime}$. The change in the Lagrangian reflects the sensitivity of the cost to $\ell$.

The derivation of the Lagrangian, $G^{T}, T=S, C$, with respect to $\ell$ yields $\frac{\partial}{\partial \ell} \mathrm{G}^{T}=$ $\sum_{\mathrm{k}} \varphi_{\mathrm{k}} \frac{\partial G^{T}}{\partial \ell}\left[t_{\mathrm{i}}-\ell\right]-\sum_{\mathrm{k}} \varphi_{\mathrm{k}}<0, \varphi_{\mathrm{k}}=\delta_{\mathrm{k}}=$ if $T=C$, and $\varphi_{\mathrm{k}}=\rho_{\mathrm{i}, \max \{\mathrm{i}+\mathrm{q}, \mathrm{N}\}}$ if $T=S$. The inequality obtains because when $\varphi_{\mathrm{k}}>0$ the term in brackets in the first argument on the right-hand side is zero. Q.E.D. 
FIGURE 1: TIME-LINE OF MAIN EVENTS

\begin{tabular}{|c|c|c|c|c|c|c|}
\hline Date 1 & Date 2 & Date 3 & Date 4 & Date 5 & Date 6 & ...Date 7 \\
\hline $\begin{array}{l}\text { The } \\
\text { principal } \\
\text { designs } \\
\text { the } \\
\text { contract, } \\
T \text {. }\end{array}$ & $\begin{array}{l}\text { The } \\
\text { agent } \\
\text { chooses } \\
\text { effort, } a \text {. }\end{array}$ & $\begin{array}{l}\text { The } \\
\text { outcome, } \mathrm{x}, \\
\text { is realized, } \\
\text { and it is } \\
\text { observed by } \\
\text { the agent } \\
\text { alone. }\end{array}$ & $\begin{array}{l}\text { The agent } \\
\text { discloses an } \\
\text { outcome to a } \\
\text { auditor. The } \\
\text { monitor audits } \\
\text { this disclosure. }\end{array}$ & $\begin{array}{l}\text { The } \\
\text { principal } \\
\text { receives } \\
\text { the } \\
\text { audited } \\
\text { public } \\
\text { report, } r \text {. }\end{array}$ & $\begin{array}{l}\text { The agent } \\
\text { is paid } t \\
\text { and quits. }\end{array}$ & $\begin{array}{l}\text { The principal } \\
\text { collects his residual } \\
\text { share, } x-t(r) \text {. }\end{array}$ \\
\hline
\end{tabular}


FIGURE 2: AN ILLUSTRATION OF A PURE-

STRATEGY RMC WHEN N=5 $(q=1)$

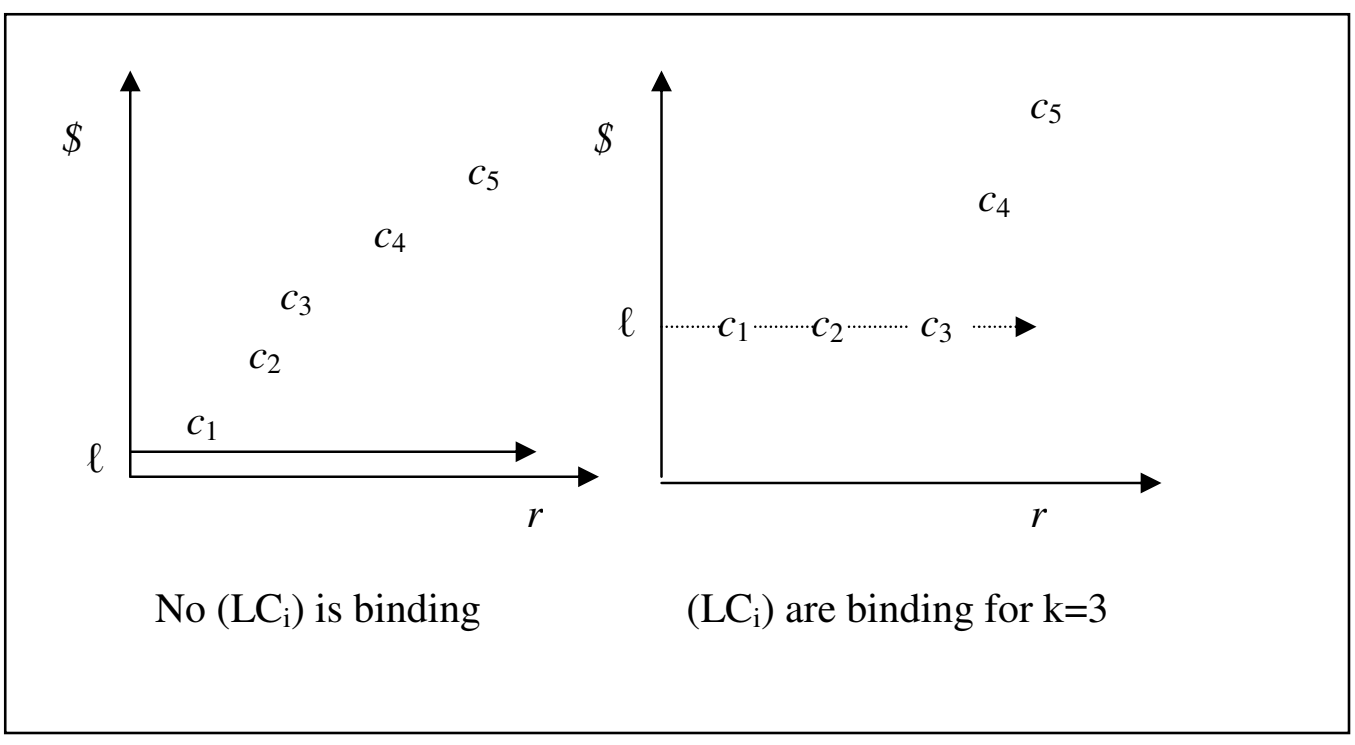


FIGURE 3: THE RELATIONSHIP BETWEEN TIC

PAYMENTS AND THE OUTCOME REPROTED TO THE PRINCIPAL WHEN N=5 AND q=2

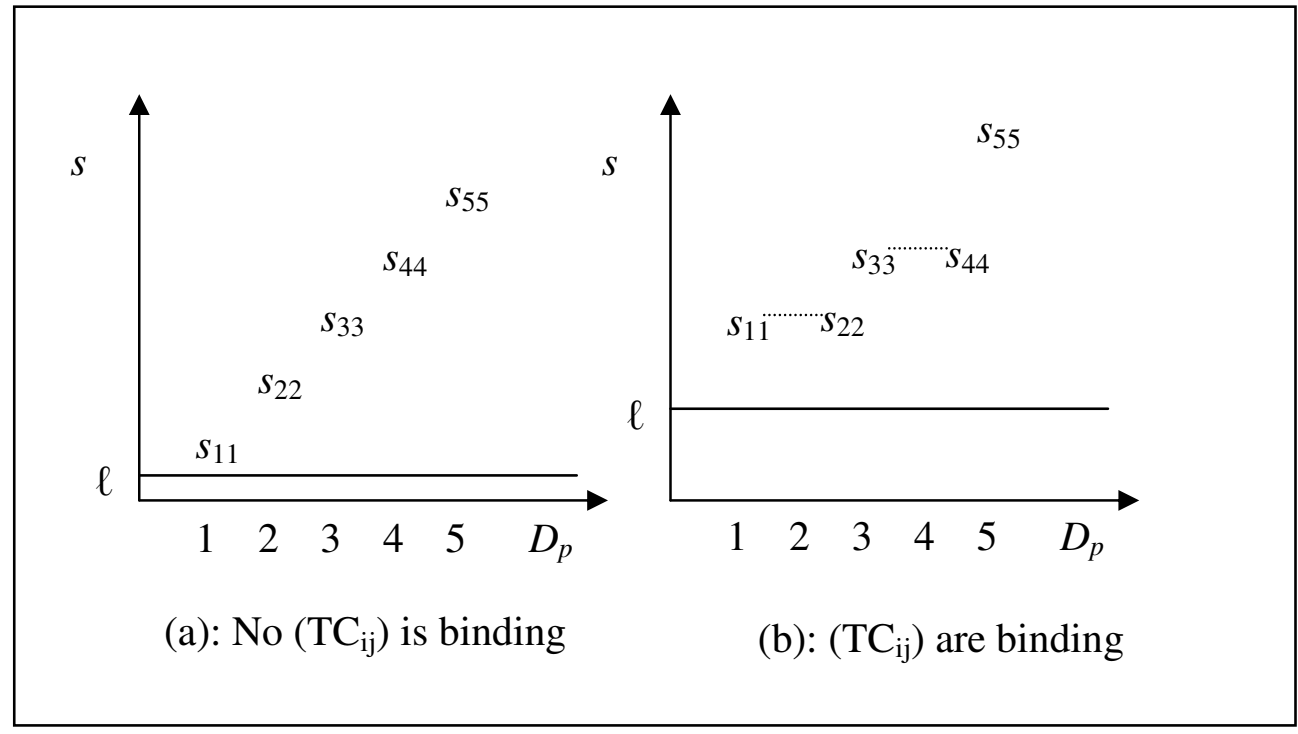


FIGURE 4: THE EXPECTED PAYMENT UNDER RMC

AS A FUNCTION OF REPORTING FLEXIBILITY

CONDITIONAL ON REALIZED OUTCOME ( $\mathrm{N}=14$ AND THE LL LEVEL IS 30)

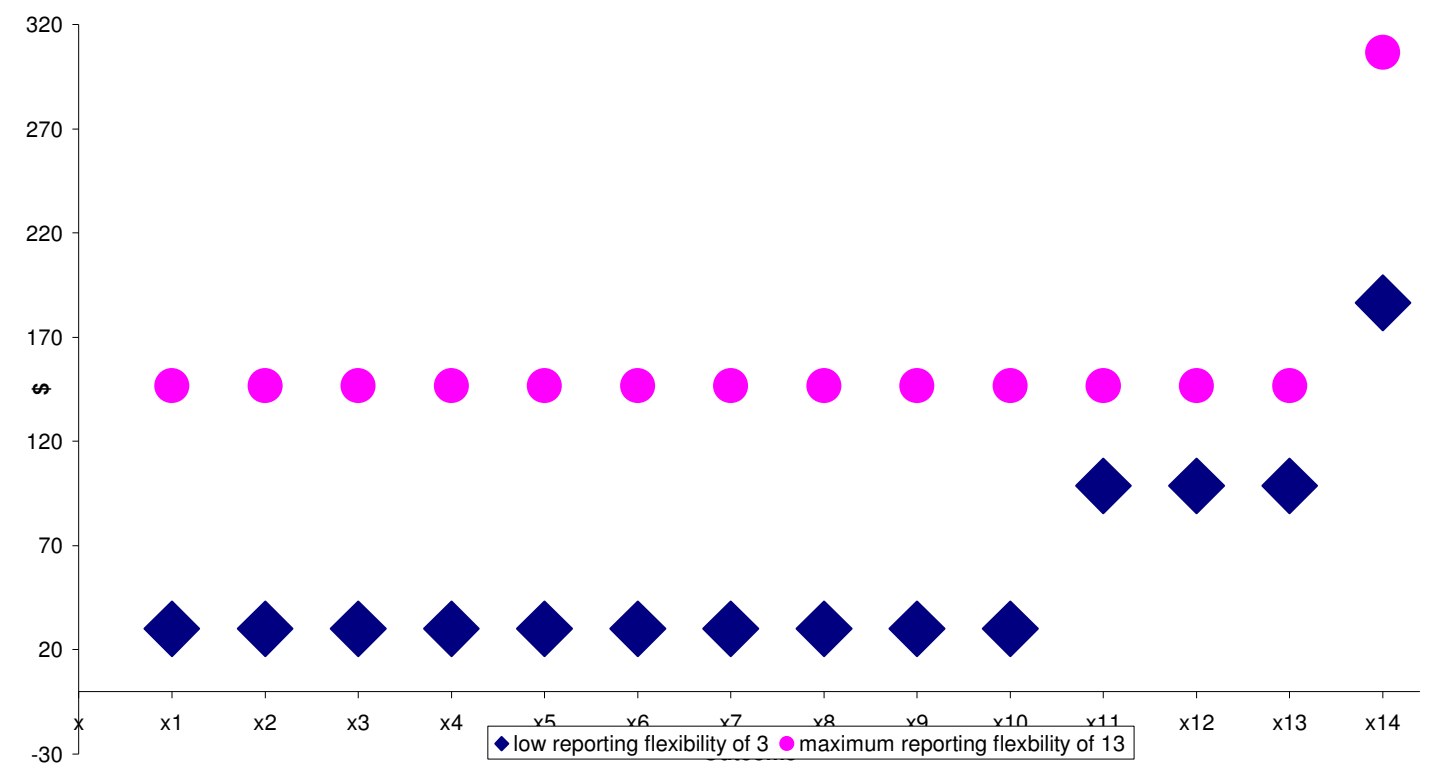


FIGURE 5: THE RELATIONSHIP BETWEEN THE RISKINESS OF RMC AND REPORTING FLEXIBILITY ( $\mathrm{N}=14)$

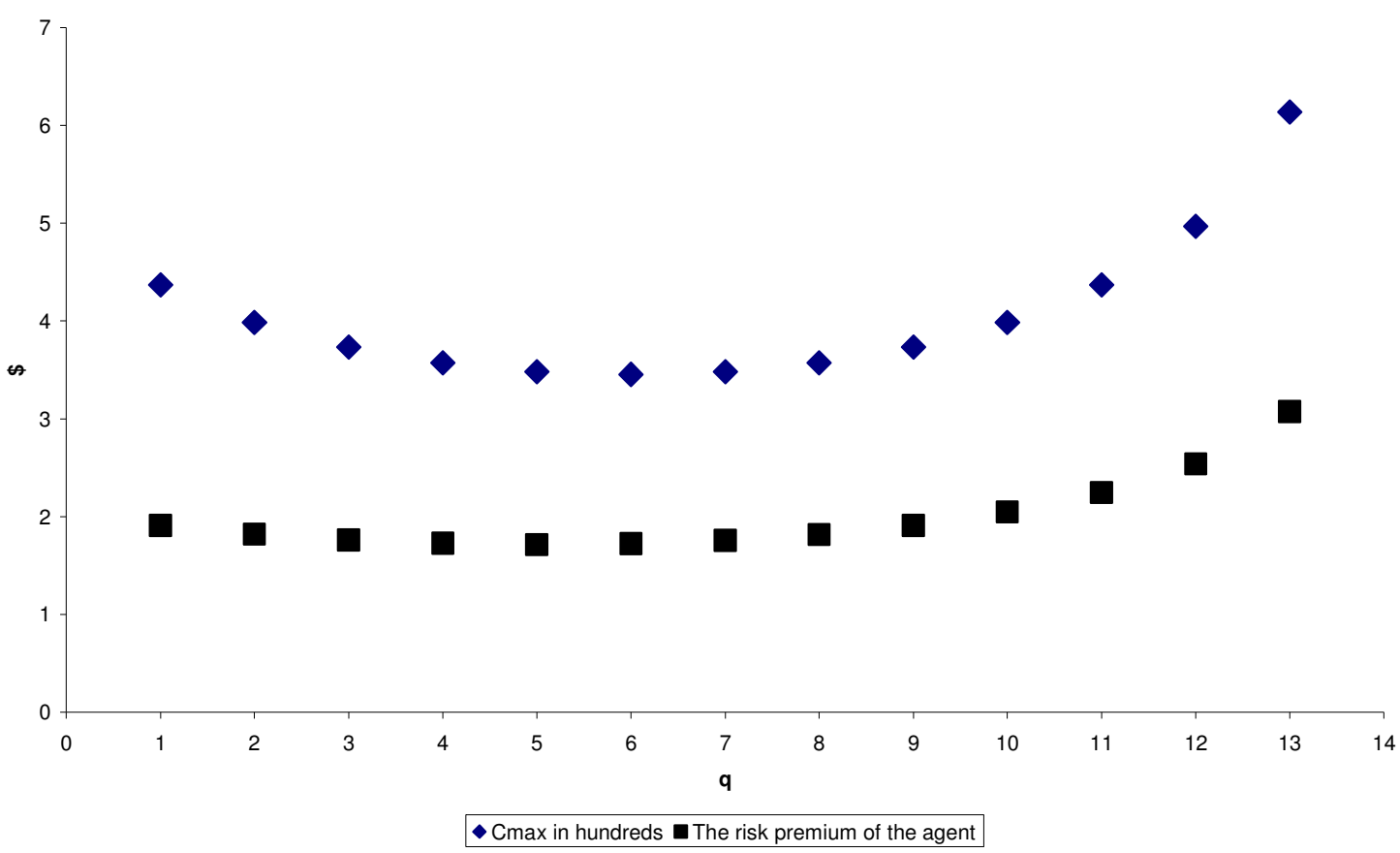


FIGURE 6: THE SAVINGS IN CONTRACTING COSTS UNDER RMC

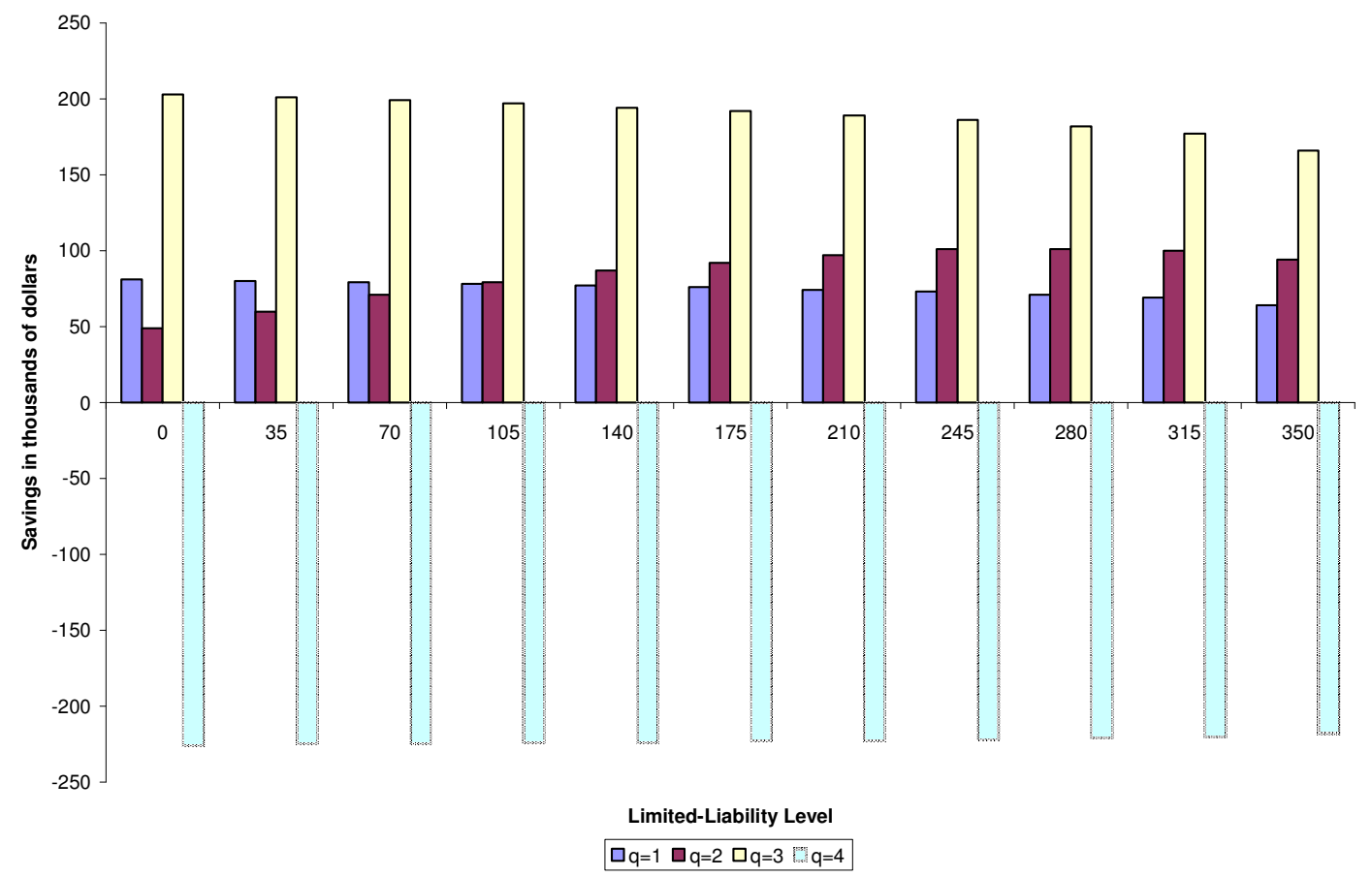

